\title{
Pseudomonas fluorescens Induces Strain-Dependent and Strain-Independent Host Plant Responses in Defense Networks, Primary Metabolism, Photosynthesis, and Fitness
}

\author{
David J. Weston, Dale A. Pelletier, Jennifer L. Morrell-Falvey, Timothy J. Tschaplinski, Sara S. Jawdy, \\ Tse-Yuan Lu, Sara M. Allen, Sarah J. Melton, Madhavi Z. Martin, Christopher W. Schadt, Abhijit A. Karve, \\ Jin-Gui Chen, Xiaohan Yang, Mitchel J. Doktycz, and Gerald A. Tuskan
}

Biosciences Division, Oak Ridge National Laboratory, Oak Ridge TN, 37831, U.S.A.

Submitted 6 October 2011. Accepted 21 February 2012.

\begin{abstract}
Colonization of plants by nonpathogenic Pseudomonas fluorescens strains can confer enhanced defense capacity against a broad spectrum of pathogens. Few studies, however, have linked defense pathway regulation to primary metabolism and physiology. In this study, physiological data, metabolites, and transcript profiles are integrated to elucidate how molecular networks initiated at the rootmicrobe interface influence shoot metabolism and wholeplant performance. Experiments with Arabidopsis thaliana were performed using the newly identified $P$. fluorescens GM30 or P. fluorescens Pf-5 strains. Co-expression networks indicated that Pf-5 and GM30 induced a subnetwork specific to roots enriched for genes participating in RNA regulation, protein degradation, and hormonal metabolism. In contrast, only GM30 induced a subnetwork enriched for calcium signaling, sugar and nutrient signaling, and auxin metabolism, suggesting strain dependence in network architecture. In addition, one subnetwork present in shoots was enriched for genes in secondary metabolism, photosynthetic light reactions, and hormone metabolism. Metabolite analysis indicated that this network initiated changes in carbohydrate and amino acid metabolism. Consistent with this, we observed strain-specific responses in tryptophan and phenylalanine abundance. Both strains reduced host plant carbon gain and fitness, yet provided a clear fitness benefit when plants were challenged with the pathogen $P$. syringae DC3000.
\end{abstract}

Microbial interactions elicit a range of host plant responses from antagonistic or neutral reactions to beneficial reactions that confer enhanced fitness. The discovery that some rhizobacteria can enhance plant growth after root colonization is one example of a beneficial interaction, and these bacteria have been appropriately termed plant-growth-promoting rhizobacteria (PGPR) (Kloepper and Schroth 1978; Lugtenberg and Kamilova 2009; Nelson 2004). The interaction between PGPR and plants occurs at the root interface where bacterial growth is promoted by root exudates while, concomitantly, the bacte-

Corresponding author: D. J. Weston; Telephone: +1.865 .241 .8323 ; Fax: +1.865.576.9939; E-mail: westondj@ornl.gov

* The $e$-Xtra logo stands for "electronic extra" and indicates that five supplementary tables are published online. ria enhance plant growth and suppress disease (van Loon 2007). This interaction is exemplified by immense diversity in the phylogenetic richness of PGPR, the multiple modes of action by which these diverse microbial associates influence plant growth, and the pathways altered within the plant host.

There are over two dozen genera of rhizobacteria reported to confer biocontrol or plant-growth-promoting traits to date, with additional genera being discovered (Kim et al. 2011). For example, Saikia and associates (2011) cultured 25 fluorescent pseudomonads from rhizospheric soil of tea plants and found that most of the isolates had strong antagonistic activity against numerous plant fungal pathogens. Multiple mechanisms were found to account for this antagonistic activity, including production of siderophores, salicylic acid (SA), hydrogen cyanide, or chitinase (Saikia et al. 2011). A similar approach was used to characterize rhizobacteria in wheat fields, where 17 isolates from multiple genera were found to promote plant growth through nitrogen fixation, auxin production, or phosphate solubilization (Venieraki et al. 2011). Another study investigating rhizobacteria from saline soils within wheat fields found evidence of plant growth promotion through auxin, gibberellin, or siderophore production as well as phosphorous solubilization (Upadhyay et al. 2009). Such studies have led to the generalization that rhizobacteria can promote plant growth through multiple modes of action, categorized as nitrogen fixation, ion uptake (especially $\mathrm{Fe}$ and $\mathrm{P}$ ), production of plant hormones, and modulation of plant development (e.g., ACC deaminase) (van Loon 2007).

In addition to the indirect effects on plant growth described above, rhizobacteria can promote host growth through direct antagonism to deleterious microorganisms through antibiotic production and competition for nutrients (Handelsman and Stabb 1996; van Loon 2007) or by priming the plant for enhanced defense through local and systemic signaling. PGPRinduced systemic defense signaling was elegantly discovered when Pseudomonas bacteria were inoculated into the rhizosphere while the pathogen was inoculated to aerial stems (van Peer et al. 1991) and leaves (Gang et al. 1991), resulting in an observed reduction in disease severity (Bakker et al. 2007). This response has since been termed induced systemic resistance (ISR) and is mediated by a myriad of rhizobacteria and biological control agents in addition to Pseudomonas spp. Investigations using Arabidopsis mutants found that induction of ISR with $P$. fluorescens WCS417r was independent of the SA pathway yet required functioning jasmonic acid (JA) and ethyl- 
ene pathways (Pieterse et al. 1996, 1998). Systemic acquired resistance (SAR) is the other known plant systemic defense pathway and differs from ISR by requiring a functioning SA pathway but is not dependent on JA or ethylene pathways (Durrant and Dong 2004).

Despite considerable advances in our understanding of PGPR-mediated host plant systemic defense, there are relatively few studies that place such results within a global view that links defense pathways to consequences on core metabolism and physiology; for example, transcriptomic studies investigating the colonization of Pseudomonas fluorescens WCS417r to Arabidopsis (Verhagen et al. 2004), Bradyrhizobium sp. strain ORS278 with Arabidopsis (Cartieaux et al. 2008), and $P$. fluorescens FPT9601-T5 with Arabidopsis (Wang et al. 2005). Similarly, few studies have looked at the consequences of PGPR on host plant physiology (e.g., photoprotective mechanisms) (Bashan et al. 2004) or comprehensive metabolic profiles (Walker et al. 2011). Therefore, insight into the conservation or diversification of host plant responses to PGPR inoculation is limited. Integration of multi-omics data offers an opportunity by which the consequences of PGPR inoculation on plant physiology and multi-organ signaling can be dissected.

The objective of this work was to investigate the consequences of PGPR $P$. fluorescens strains on host plant transcript and metabolic profiles and then link these results to physiological scales using network analysis techniques. Our study uses a newly discovered P. fluorescens strain from the Populus deltoides rhizosphere and places this strain within a comparative context with the well-studied PGPR Pseudomonas fluorescens Pf-5 strain (Loper et al. 2007). Similar to previous transcriptomic studies characterizing $P$. fluorescens (Verhagen et al. 2004; Wang et al. 2005); we use Arabidopsis thaliana as the plant host. Specifically, we address the following questions: i) does the newly discovered $P$. fluorescens strain (GM30) colonize plant roots, ii) does GM30 elicit a host plant response similar to the known PGPR Pf-5, and iii) what are the consequences of GM30- and Pf-5-induced defense response on host plant primary metabolism and physiology?

\section{RESULTS}

\section{GM30 characterization.}

In an attempt to characterize the microbiome of native $P$. deltoides rhizosphere, we have isolated several hundred bacterial strains from surface sterilized roots of native trees collected in central Tennessee (Gottel et al. 2011). After screening these isolates for plant-growth-promoting effects, isolate GM30 was found to elicit enhanced lateral root formation when co-cultured with Arabidopsis. Biochemical and morphological analysis demonstrated that strain GM30 formed circular white-yellow colonies that became mucoid and produced a diffusible fluorescent pigment after $48 \mathrm{~h}$ of growth on R2A agar. Microscopic observation indicated that GM30 cells are non-spore-forming motile rods, approximately 1 by $2 \mu \mathrm{m}$ in size. GM30 was tested for a number of rhizosphere competence traits and was found to produce siderophore and protease activity based on chrome azurol-S and skim milk agar assays, respectively, but tested negative for phosphatase activity (Supplementary Table S5). In addition, gas chromatography-mass spectrometry (GC-MS) analysis demonstrated that GM30 produced $0.76 \mathrm{nM}$ indole-3-acetic acid (IAA) when grown in R2A media for $24 \mathrm{~h}$ (data not shown). The production of siderophores, IAA, and protease activity are all characteristics common to rhizosphere isolates of $P$. fluorescens (O'Sullivan and Ogara 1992). Phylogenetic analysis of strain GM30 by $16 \mathrm{~S}$ $r R N A$ and $r p o D$ gene sequences identified the strain as a member of the $P$. fluorescens clade (Fig. 1). In this group, strains $P$. koreensis (Kwon et al. 2003) and P. fluorescens Pf0-1 (Silby et al. 2009) are most closely related to strain GM30.

\section{Evidence for GM30 and Pf-5 interaction with roots.}

Imaging was used to determine whether GM30 physically associated with Arabidopsis roots, as would be expected based on its isolation from rhizosphere samples. Initial studies were conducted using Arabidopsis plants grown in sterile soil and inoculated with Pf-5, GM30, or uninoculated culture media as a control. In this study, GM30 and Pf-5 were found associated

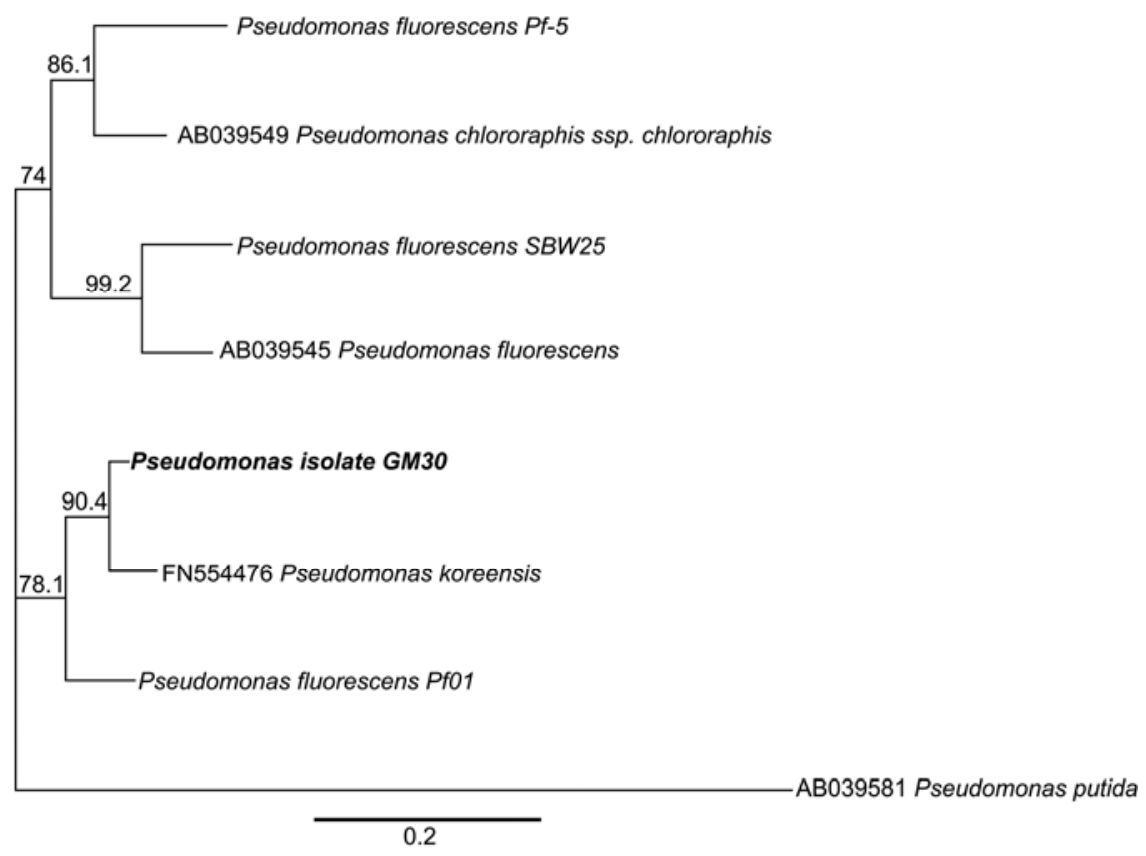

Fig. 1. Phylogenetic analysis of Pseudomonas spp. maximum-likelihood tree of $r p o D$ from the GM30 isolate derived from Populus deltoides (bold italic), other known plant-growth-promoting rhizobacteria strains of Pseudomonas fluorescens sequenced as references in this study (italic), and reference strains of closely related Pseudomonas spp. available from GenBank. P. putida is used as an outgroup. Bootstrap values $>50$ are shown inside the nodes and reflect 1,000 resamplings. 
with plant roots as determined by fluorescent in situ hybridization (FISH) using GAM42a-Alexa488, a $\gamma$-proteobacteria-specific probe that recognizes GM30 and Pf-5 (Fig. 2B and C). Although double-autoclaved soil was used for this experiment, additional microbes were present in the samples as determined by co-labeling the samples with EUB338-Alexa594, which recognizes all bacteria (Fig. $2 \mathrm{~A}$ to $\mathrm{C}$, red bacterial cells). The localization of both GM30 and Pf-5 were also investigated in Arabidopsis plants grown in a controlled axenic system. These data show that GM30 is physically associated with plant roots and is typically found on the outer surface of the root (Fig. $2 \mathrm{~F})$. This localization pattern is similar to that of Pf-5 co-cultured under the same conditions (Fig. 2E). Few additional bacteria were found in control plants, verifying the axenic tissue culture conditions (Fig. 2D).

\section{Transcript profiling of Arabidopsis colonized by GM30 and Pf-5.}

To investigate the local and systemic response of Arabidopsis to Pf-5 and GM30 root colonization, transcript profiles for Arabidopsis Col-0 plants were taken for both roots and shoots. A prior transcript profiling study reported that rhizobacteriainduced systemic defense in Arabidopsis was established within 7 days after co-culture with $P$. fluorescens WCS $417 \mathrm{r}$ (Verhagen et al. 2004). To capture the early onset of this systemic response and ease comparison with like studies, we followed the collection regime of Verhagen and associates (2004) by sampling at 3 and 7 days after co-culture treatment.
Genes having a Bonferroni adjusted $P \leq 0.05$ and a log-odds ratio $>1.4$, as determined from the limma package (Smyth 2005) operated within the $\mathrm{R}$ statistical language, were deemed significantly differentially expressed. Results from this stringent gene selection criteria identified 1,007 and 338 Arabidopsis genes that were significantly differentially expressed relative to the broth control on day 3 after co-culture for GM30 and Pf-5, respectively. Most of the differentially expressed genes were in roots, with only 10 and $5 \%$ of the genes found within shoots of GM30 and Pf-5 co-cultured plants, respectively. The number of differentially expressed genes was greatly reduced by day 7 , with only 163 genes meeting our differential gene expression criteria for both co-culture treatments and organs.

The PageMan (Usadel et al. 2006) and MapMan (Thimm et al. 2004; Usadel et al. 2009) bioinformatics software packages were used to infer changes in primary metabolism, cellular pathways, and hormonal regulation underlying local and systemic genomic reprogramming. Under- and over-represented functional groups were determined based on Fisher's exact test and Wilcoxon rank summary test statistics with Bonferroni correction for multiple testing and displayed using false colors. Alterations in functional group categories were most prevalent for the local root response on day 3 after treatment (Fig. 3). Induction of nitrate metabolism, reduction, and branched chained amino acid synthesis, including tryptophan and sucrose synthesis, was conserved for local root response for GM30 and Pf-5 relative to control plants (Fig. 3). Diversification was also observed in roots, with induction of glucosonilates, abscissic
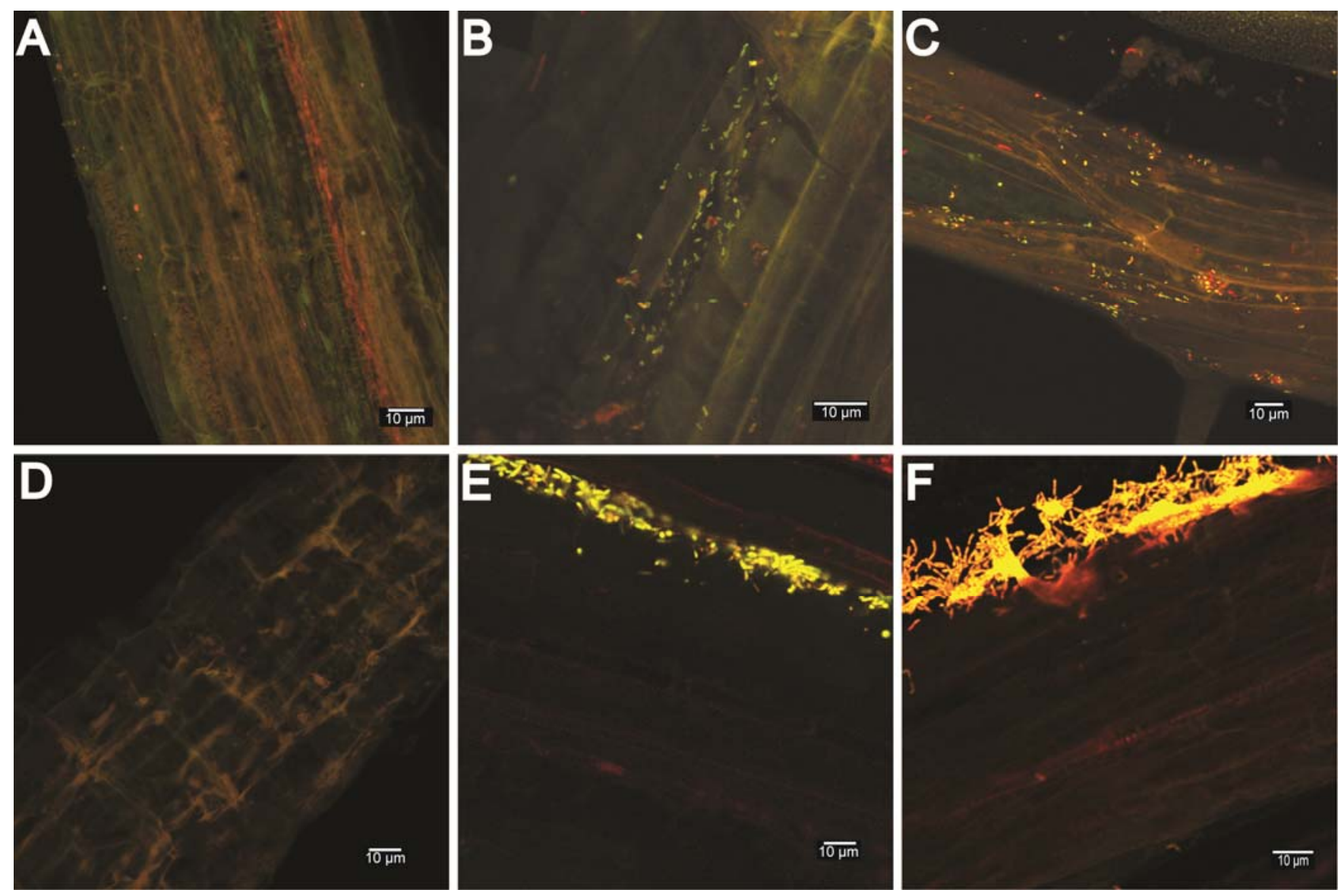

Fig. 2. Bacterial strains Pf-5 and GM30 physically associate with plant roots. Roots of Arabidopsis seedlings grown in soil and inoculated with A, media alone; B, Pf-5; or C, GM30 were harvested after 3 days and fixed in $4 \%$ paraformaldehyde. Bacteria were localized by fluorescent in situ hybridization (FISH) using an Alexa-488 conjugated probe specific to $\gamma$-proteobacteria (green; GAM42a-Alexa488) for detection of Pf-5 or GM30 and an Alexa-594 conjugated universal bacterial probe (red; EUB338-Alexa594). Arabidopsis seedlings grown in axenic systems in the D, absence or presence of E, Pf-5 or F, GM30 were harvested after 10 days and fixed in 4\% paraformaldehyde. D and E, FISH was performed using a Pseudomonas spp.-specific probe (PSP1284Alexa-488) and EUB338-Alexa594; F, FISH was performed with GAM42a-Alexa488 and EUB338-Alexa594. 
acid (ABA) synthesis, and signal transduction and ethylene metabolism specific to GM30 relative to Pf-5 and control plants at day 3 .

The systemic response was more specific to bacteria type, with GM30 plants showing over-representation in genes for glucosinilate synthesis, ABA, and gibberellin metabolism (Fig. 3). Plants inoculated with Pf-5 showed induction for genes contributing to tryptophan degradation, auxin metabolism, and JA metabolism (Fig. 3). Although inferred functional categories were less responsive at day 7 , there were some notable systemic responses. These include repression in asparagine synthesis and induction in ABA signal transduction and raffinose synthase for GM30- and Pf-5-inoculated plants (Fig. 3).

\section{Pathway visualization and integration}

of metabolites and transcripts.

To confirm inferred pathway alterations from transcript profiles, metabolite changes in targeted pathways reflective of pri-

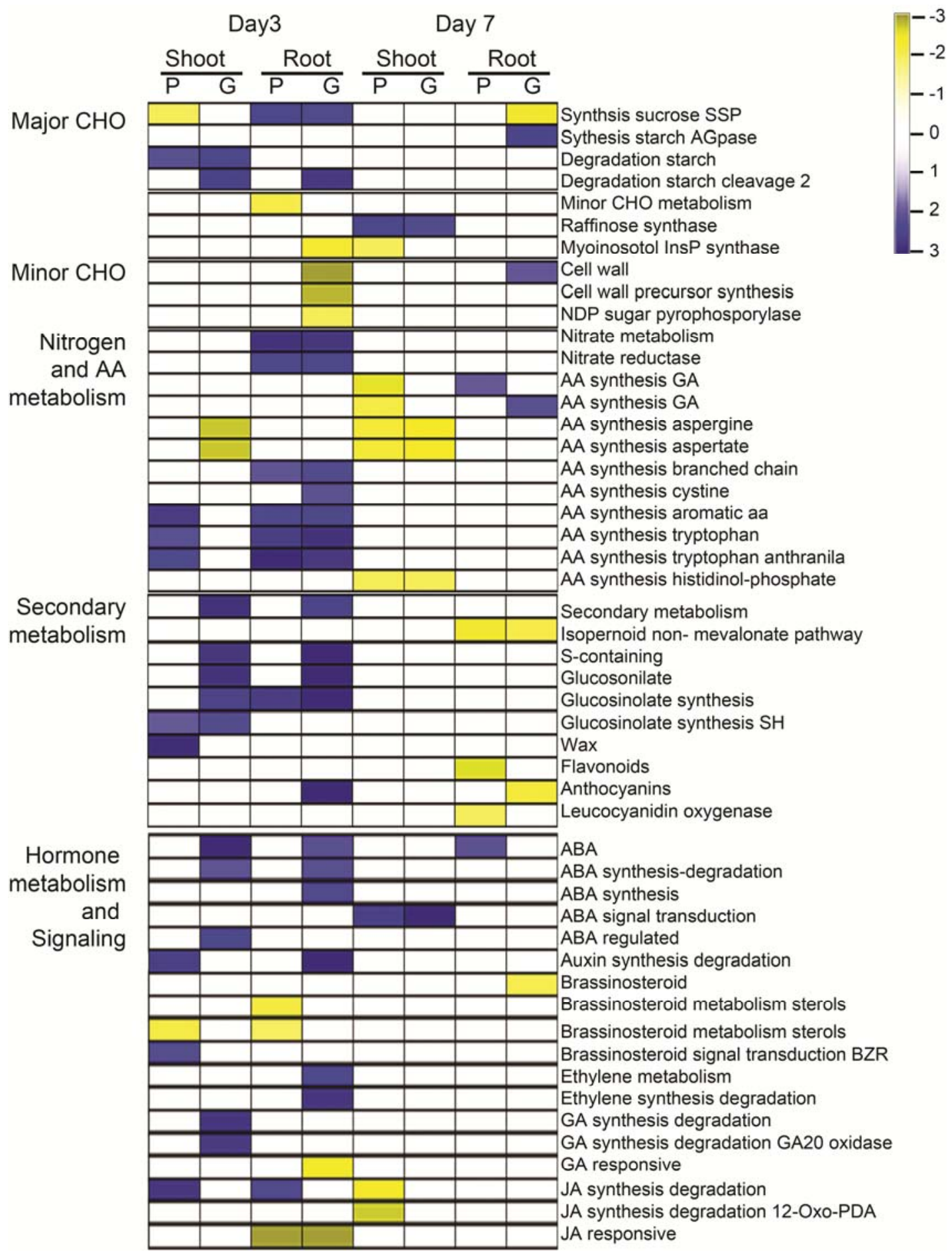

Fig. 3. Inferred pathway analysis from gene expression data and PageMan display of selected gene categories for primary and secondary metabolism pathways. An unpaired Wilcoxon rank sum test was used to determine whether the median fold-change within a particular ontological group is the same as the median fold-change of all genes not in that group for Pf-5 (P) and GM30 (G). Multiple testing was corrected with Benjamini Hochberg. Resultant $P$ values were transformed to $z$ values with $P \leq 0.05$ set to 0 . False colors are used to distinguish among over- and under-represented (blue and yellow, respectively) categories. 
mary metabolism were plotted with respective transcripts (Fig. 4). The response of measured metabolites from Arabidopsis shoots was, in general, similar between Pf-5 and GM30 cocultured plants, with a few notable exceptions. For example, increases in phenylalanine and tryptophan induction for GM30 and suppression for Pf-5 were observed (Fig. 4). In addition to differences in directional trends for some metabolites, there were differences in the magnitude of the response. For example, both GM30 and Pf-5 co-cultured plants showed similar trends in induction of methionine and aspartate through time, yet the induction is greater for Pf-5- relative to GM30-inoculated plants (Fig. 4). Similarly, asparagine reduction was observed for both bacterial isolates, yet the magnitude of the response was greater for Pf-5 relative to GM30 (Fig. 4).
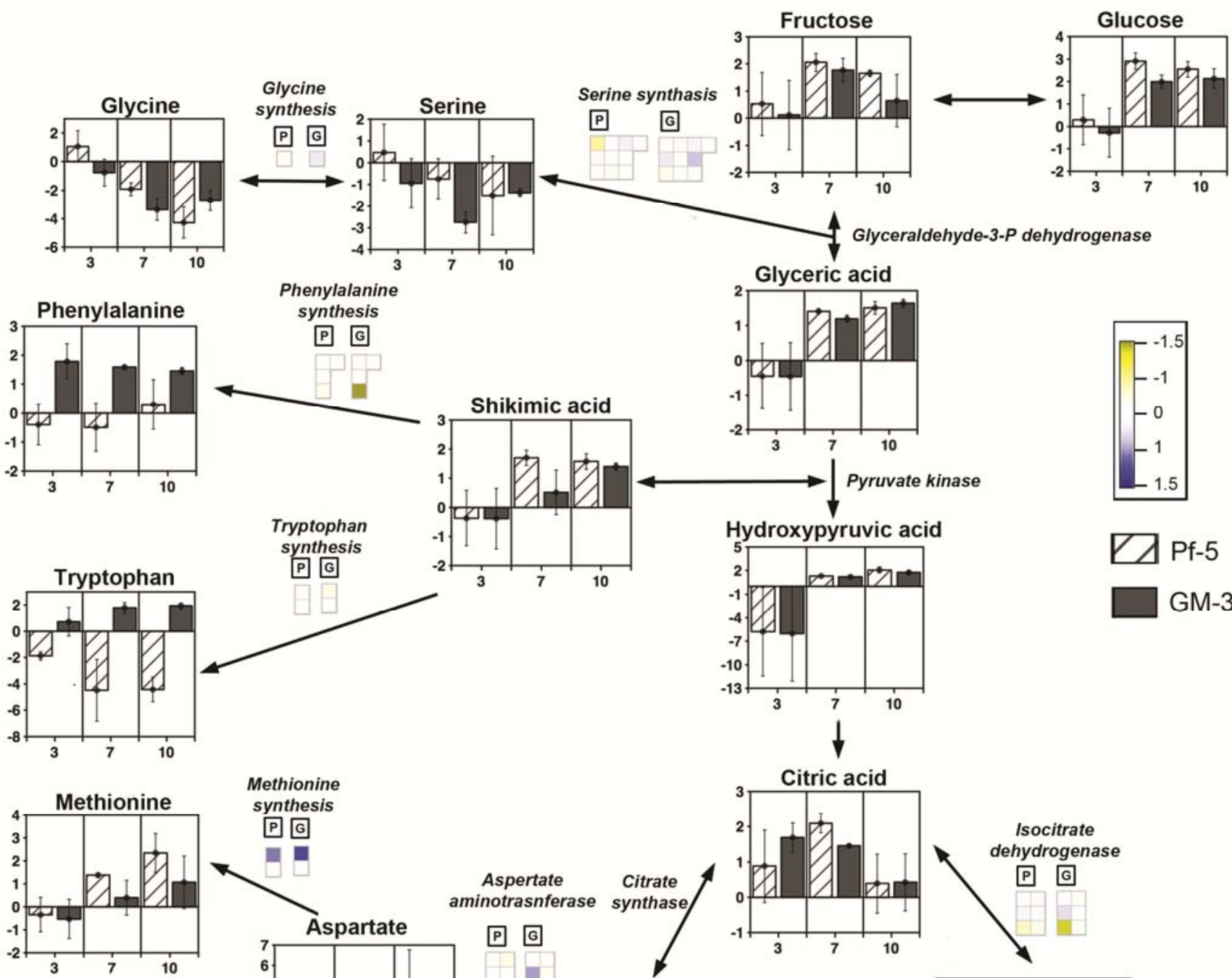

Methionine

Citric acid

(

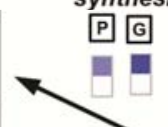

ㅁ.

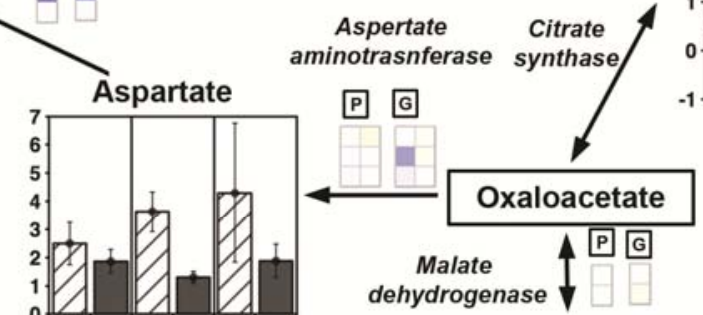

Aspertate

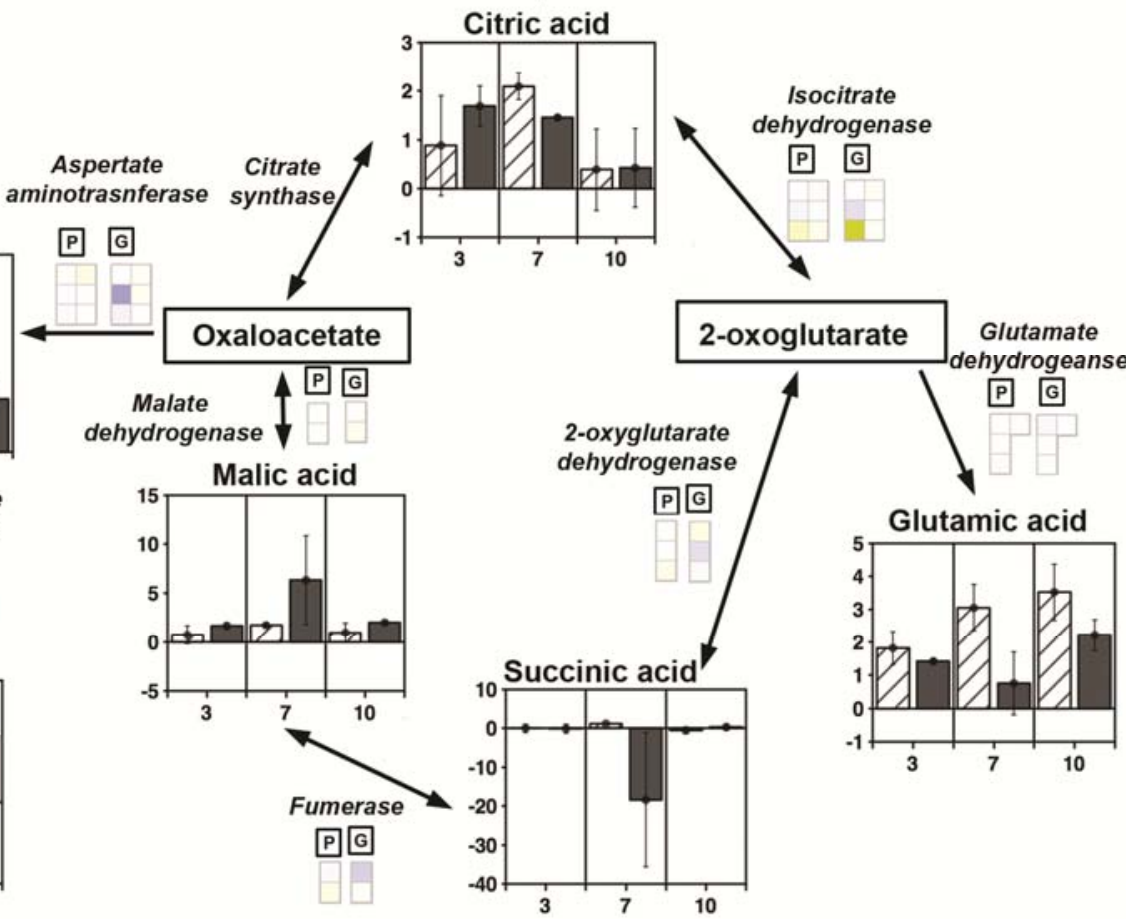

Aspargine synthase P. $\mathrm{G}$
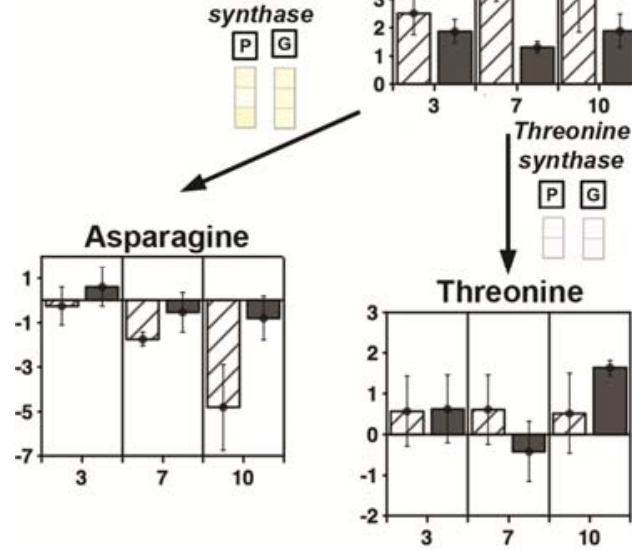

Fig. 4. Integrated gene expression and metabolite profiles for glycolysis, TCA cycle, and amino acid metabolism. Metabolites are represented in bar plots for Arabidopsis shoots after inoculation with GM30 (solid bars) or Pf-5 (striped bars). The $x$ axis represents days after inoculation and the $y$ axis is log-fold change relative to broth control plants. Transcript abundance changes for the corresponding enzymes are presented as log fold-change for Pf-5 (P) and GM30 (G) relative to control plants using the color bar. False colors are used to distinguish among induced and suppressed transcripts. 
Quantitative reverse-transcription polymerase chain reaction (qRT-PCR) validation and marker gene response at early and late onset of induced systemic response.

Transcript and metabolite analyses indicate strain-dependent alterations in host primary metabolism. An additional independent study under axenic conditions was conducted to validate array results, add finer time scales to the expression analysis, and link primary metabolism changes to previous investigations on systemic defense. Transcript abundance was estimated for leaves using a high-throughput robotic qRT-PCR system targeting known marker genes along with signaling, hormone, and defense pathways at $12 \mathrm{~h}, 24 \mathrm{~h}, 48 \mathrm{~h}, 7$ days, and 10 days after co-culture inoculation. Trends for the calcium-binding protein 20 (CBP20) (Vadassery et al. 2009) marker gene were similar between co-culture conditions, yet there was a notable increase in the azelic acid (Azl1; At4g12470) (Jung et al. 2009) marker gene at $24 \mathrm{~h}$ after GM30 co-culture relative to Pf-5 co-cultured plants (Fig. 5A). The indole-acetic early response gene IAA1 (At4g14560) (Soeno et al. 2010) decreased

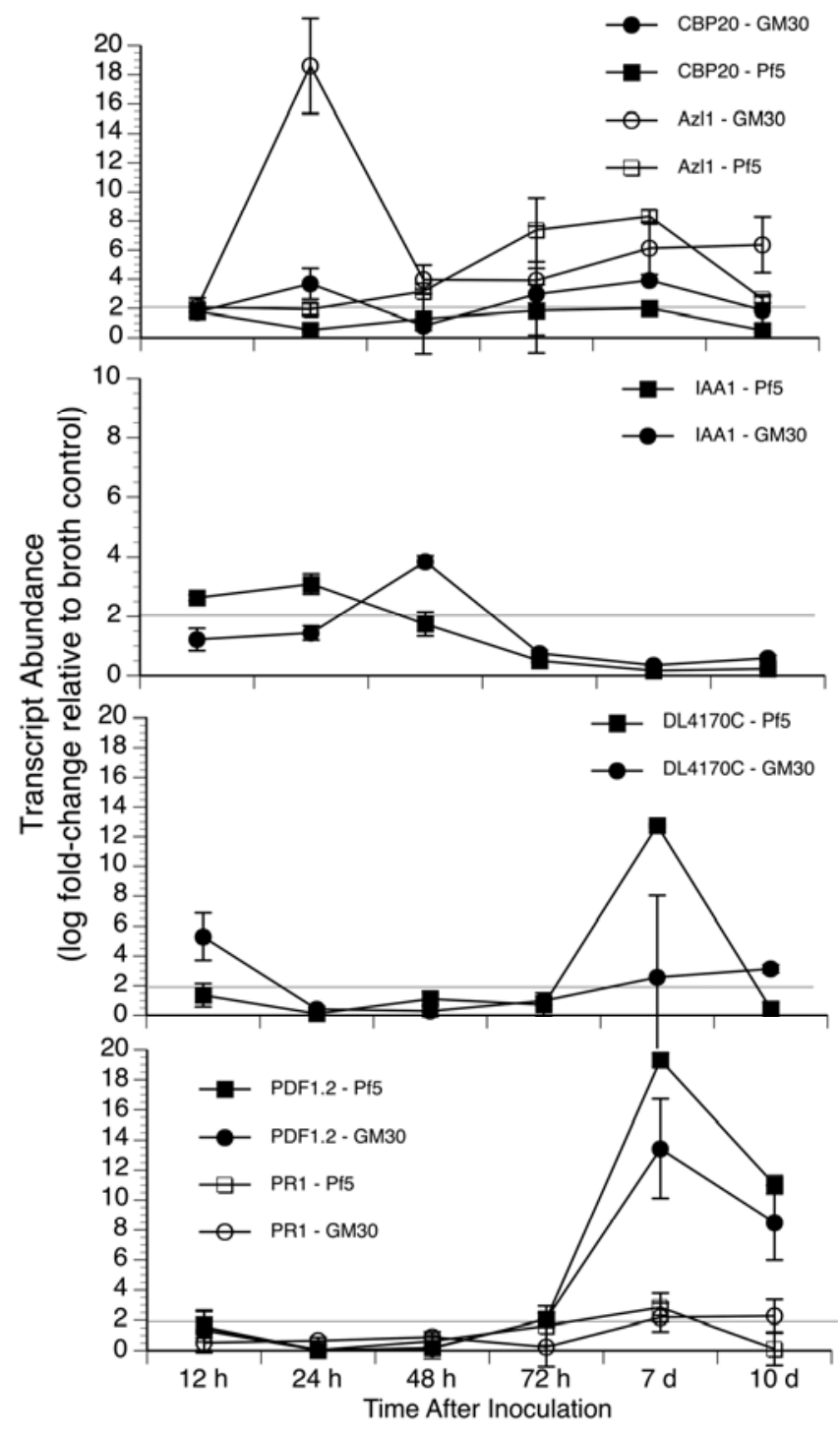

Fig. 5. Transcript abundance of known marker genes in plant-microbe interactions. Marker genes include calmodulin-binding protein CBP20 (At5g26920), azelaic acid responsive Azi1 (At4g12470), auxin responsive IAA1 (At4g14560), glycosyl hydrolase DL4170C (At4g16260), plant defensin PDF1.2 At5g44420, and pathogenesis-related protein-1 PR1 (At2g14610). Marker gene citations and primer design are provided in Supplementary Table S4. after $24 \mathrm{~h}$ for Pf-5 co-cultured plants while there was a spike in IAA1 expression at $48 \mathrm{~h}$ for GM30 plants (Fig. 5B). The expression of glycosyl hydrolase marker DL4170C (At4g16260) (Soeno et al. 2010) was greatest at day 7 for Pf-5 plants and rose slightly on the same day for GM30 plants, although there is considerable variation in mean response (Fig. 5C). The defense marker gene PR1 (At2g14610) (Vadassery et al. 2009) was relatively flat throughout the measurement period whereas the methyl-jasmonate-induced plant defensin gene, PDF1.2 (Pozo et al. 2008), increased in abundance at day 7 after coculture with both Pf-5 and GM30 (Fig. 5D).

\section{Co-expression network analysis and comparison with like studies.}

A weighted gene co-expression network was generated for the 1,700 most differentially expressed (most significant $F$ test among all three contrasts) genes. This network approach is composed of modules that contain genes with high topological overlap, which is representative of the relationship similarity between the expression of two genes relative to all other genes within the network. Thus, modules contain genes sharing highly correlated expression patterns that are typically involved in the same biological function (Barabasi and Oltvai 2004; Subramanian et al. 2005). This has been referred to as the "guilt by association" paradigm (Usadel et al. 2009).

The network algorithms generated five modules for the Arabidopsis transcriptome under broth control, GM30, and Pf-5 coculture conditions (Fig. 6; Supplementary Table S3). The eigenvalue for each module was correlated to treatment to identify patterns of module expression and, thus, potential underlying subnetworks driving primary metabolism and defense response. The brown module eigenvalue was positively correlated with roots co-cultured with Pf-5 (Pearson $r=0.61, P=7 \times 10^{-3}$ ) and GM30 (Pearson $r=0.57, P=1 \times 10^{-2}$ ), suggesting that this module is independent of the co-cultured bacterial strain. Enrichment analysis indicated that this module was over-represented with genes participating in RNA regulation, protein degradation, and hormonal metabolism. Alternatively, the strong positive correlation (Pearson $r=0.9, P=5 \times 10^{-7}$ ) between the green module eigenvalue and roots was only apparent with those inoculated with GM30, suggesting a strain-dependent response. Enrichment analysis indicated that the green module was over-represented with genes participating in calcium signaling, sugar and nutrient signaling, and auxin metabolism.

As expected, the relationship between network expression and systemic shoot response was weak, yet still apparent for the turquoise module eigenvalue to GM30-inoculated shoots (Pearson $r=0.51, P=0.03$ ) and perhaps Pf-5-inoculated shoots (Pearson $r=0.45, P=0.06$ ). Enrichment analysis indicated that this module was over-represented with genes participating in secondary metabolism, including sulfur containing glucosinolates, photosynthetic light reactions, and hormone metabolism.

To place our network results within the broader context of Pseudomonas-Arabidopsis interactions, we mined the limited microarray data available for this system, including an interaction study of Arabidopsis with P. fluorescens FPT9601-T5 using a 22,810-feature ATH1 array (Wang et al. 2005), a $P$. thivervalensis MLG45-Arabidopsis interaction study with a 14,300-feature cDNA array (Cartieaux et al. 2003), and a $P$. fluorescens WCS417r-Arabidopsis interaction study using a 8,000-feature GeneChip array (Verhagen et al. 2004). A summary table (Table 1) of the results from the above studies is presented and depicts significantly differentially expressed genes, as determined by the respective authors, within the context of our network results. There is heterogeneity among these studies in terms of array platform used, plant organ investi- 
gated, and Pseudomonas sp. and strain. Nonetheless, all studies have genes present within our network and they all enrich the turquoise module, suggesting that this module represents an underlying subnetwork driving $P$. fluorescens-mediated responses in host plant primary metabolism and defense.

\section{Host plant physiology, pathogen resistance, and defense tradeoffs.}

The consequences of Pf-5 and GM30 root colonization on host plant physiology was investigated on 7-day-old Arabidopsis seedlings grown in axenic tissue culture, then transferred to pots containing double-autoclaved soilless medium and exposed to co-culture conditions for 21 days. Chlorophyll content estimated on a fresh weight basis was 11 and $22 \%$ greater for Arabidopsis co-cultured with R2A broth (control) relative to Pf-5 and GM30 treatments, respectively $(P=0.029)$. The total concentration of host plant nonstructural proteins as determined by the Bradford assay was not significantly different among co-culture treatments $(P=0.911)$ (Table 2$)$. The trend observed for chlorophyll content was also reflected in estimates of photosynthesis. In this case, the maximum rate of $\mathrm{CO}_{2}$ assimilation at saturating light conditions was 12 and $18 \%$ greater for plants at control co-culture conditions relative to $\mathrm{Pf}-5$ and GM30, respectively $(P=0.031)$ (Table 2$)$. Leaf number was greatest for control broth conditions and decreased by 12 and $21 \%$ for Pf-5- and GM30-treated plants, respectively ( $P=$ 0.068) (Table 2). Differences in host plant leaf area were not significant in response to co-culture conditions $(P=0.151)$ (Table 2), yet increased lateral root production was observed for both Pf-5 and GM30 relative to the control (Fig. 7; Table 2). In addition, plant height and total seed production were significantly greater in broth control plants relative to both GM30- and Pf5-inoculated plants (Table 2).
Finally, a pathogen challenge was conducted to determine the consequences of induction of defense responses in Arabidopsis seedlings co-cultured with Pf-5 or GM30 for 21 days. Five days post challenge with $P$. syringae pv. tomato DC3000, the leaf tissues of Arabidopsis seedlings were assayed for the presence of the pathogen. These data indicated that inoculation of Arabidopsis with either GM30 or Pf-5 reduced $P$. syringae pv. tomato DC3000 colonization of leaf tissue $\left(1.7 \times 10^{8}\right.$ and $2.1 \times 10^{8} \mathrm{CFU}$ DC3000 $\mathrm{g}^{-1}$ of leaf tissue, respectively) by an order of magnitude compared with uninoculated control plants $\left(2.0 \times 10^{9} \mathrm{CFU}\right.$ DC3000 $\mathrm{g}^{-1}$ of leaf tissue). Furthermore, disease symptoms on host leaves

Table 1. Integration of co-expression network analysis with results from previous transcript profiling studies ${ }^{\mathrm{a}}$

\begin{tabular}{lcccc}
\hline Studies & $\begin{array}{c}\text { Number of } \\
\text { genes } \\
\text { induced }\end{array}$ & $\begin{array}{c}\text { Number of } \\
\text { genes } \\
\text { suppressed }\end{array}$ & $\begin{array}{c}\text { Associated } \\
\text { in } \\
\text { network }\end{array}$ & $\begin{array}{c}\text { Most } \\
\text { enriched } \\
\text { module }\end{array}$ \\
\hline Wang et al. & & & & \\
$\quad \begin{array}{l}\text { Shoots } \\
\text { Roots }\end{array}$ & 95 & 105 & 37 & Turquoise \\
Verhagen et al. & NA & NA & $\ldots$ & $\ldots$ \\
$\quad$ Shoots & NS & NS & $\ldots$ & $\ldots$ \\
$\quad$ Roots & 37 & 60 & 20 & Turquoise \\
Cartieaux et al. & & 21 & 6 & Turquoise \\
$\quad \begin{array}{l}\text { Shoots } \\
\text { Roots }\end{array}$ & 42 & 9 & 1 & Gray \\
\hline
\end{tabular}

${ }^{a}$ Comparisons include data from studies on Arabidopsis with Pseudomonas fluorescens FPT9601-T5 using a 22,810-feature ATH1 array (Wang et al. 2005), a $P$. thivervalensis MLG45-Arabidopsis interaction study with an 14,300-feature cDNA array (Cartieaux et al. 2003), and a P. fluorescens WCS417r-Arabidopsis interaction study using a 8,000-feature GeneChip array (Verhagen et al. 2004). NA = not applicable and NS = not significant.
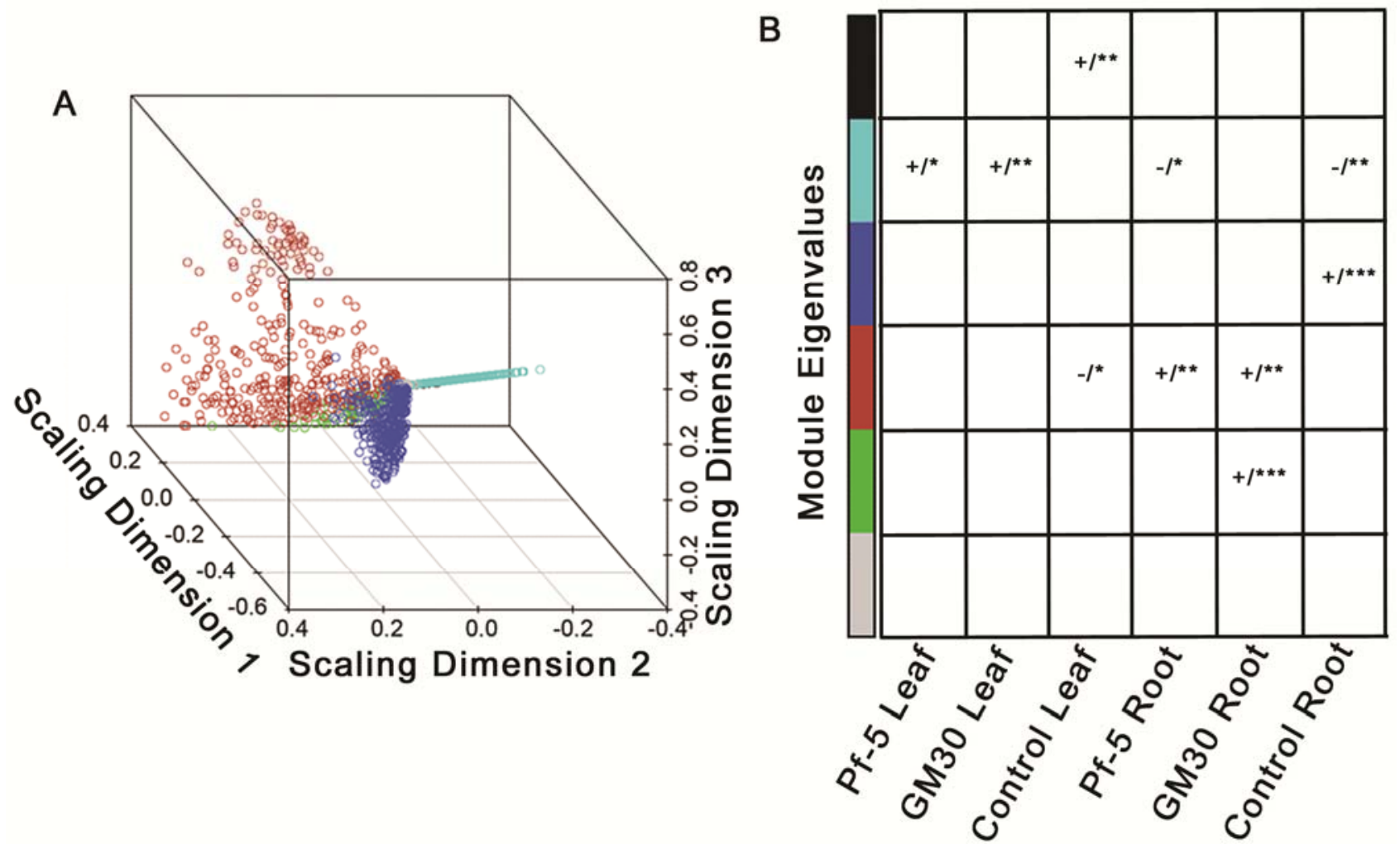

Fig. 6. Weighted gene co-expression network construction and module correlation to inoculation treatment and organ. A, Multidimensional scaling plot of the gene co-expression network. Each circle represents a single gene and color corresponds to module designation. The distance between circles is a function of topological overlap and provides a visual representation of gene and module relationships. B, Indicates the positive (+) and (-) Spearman correlation between module eigenvalue ( $y$ axis) and treatment conditions ( $x$ axis). 
were more apparent for control plants relative to GM30 and Pf-5 co-cultured plants (Fig. 7).

\section{DISCUSSION}

There is a considerable body of literature from studies investigating the mechanisms by which PGPR induce systemic host plant defense, yet integrative studies linking PGPR to host gene networks governing primary metabolism and physiology are relatively unexplored. Here, we present a study integrating physiology and metabolic and transcriptomic profiling with advances in network analytical techniques. Inoculation of plant roots with GM30 and Pf-5 elicit both conserved and strainspecific subnetworks in plant roots that, in turn, initiate a relatively conserved subnetwork driving systemic response in host shoots. Both GM30 and Pf-5 initiate conserved and strain-

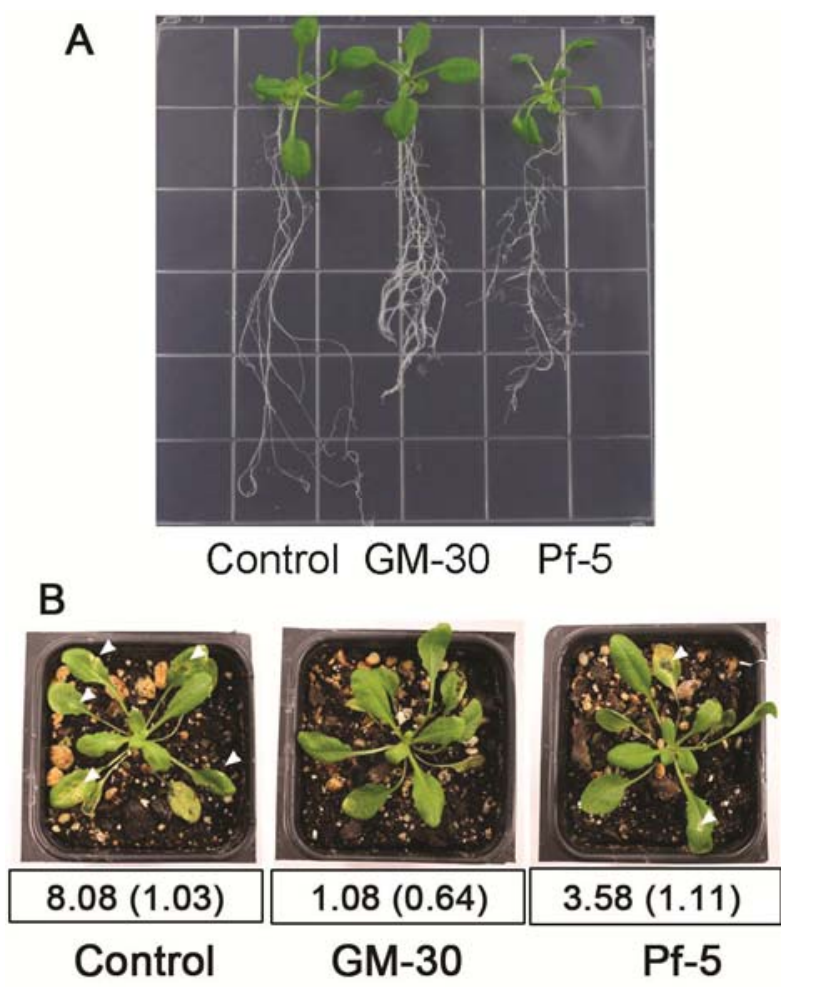

Fig. 7. Arabidopsis response to GM 30 and Pf-5 root inoculation. A, Root morphology showing increased lateral root formation for GM30 and Pf-5 relative to broth control. B, Response of host leaves to Pseudomonas syringae pv. tomato DC3000 infection after root inoculation with broth control, GM30, or Pf5. Numbers represent the mean necrotic lesions per plant $(n=15)$ and standard deviation is reported within parentheses. specific responses on plant primary metabolism that reduced net $\mathrm{CO}_{2}$ assimilation and seed production. However, this tradeoff provides a substantial fitness benefit when plants were challenged with a leaf pathogen.

\section{Does $\boldsymbol{P}$. fluorescens GM30 colonize plant roots?}

P. fluorescens GM30 is a newly identified PGPR. Profiling of native Populus deltoides roots by 454 pyrosequencing of rDNA indicated that the endophyte microbial populations are dominated by Pseudomonas fluorescens-like strains (Gottel et al. 2011). GM30 was isolated from these same surface-sterilized Populus deltoides roots and, from subsequent gene sequence analysis, we concluded that strain GM30 is a strain of Pseudomonas fluorescens. Phenotypic analysis demonstrated that strain GM30 possesses several characteristics common to other rhizosphere isolates of $P$. fluorescens, including the production of IAA, siderophores, and protease activity. In addition, inoculation of GM30 resulted in enhanced lateral root production in Arabidopsis and enhanced pathogen resistance under our experimental conditions. Consistent with its plantgrowth-promoting role, our results indicate that GM30 interacts with plants roots through a biofilm on the root surface plane. Based on its isolation, we predict that GM30 may also reside within plant tissues. Our data do not rule out this possibility; however, further testing is needed to establish this localization pattern conclusively.

\section{Does $P$. fluorescens GM30 elicit host plant networks in a manner similar to $P$. fluorescens Pf-5?}

Pf-5 was isolated from the cotton rhizosphere with resynthesis studies demonstrating disease symptom suppression from the widespread pathogens Rhizoctonia solani and Pythium ultimum on cotton, cucumber, pea, and maize (Howell and Stipanovic 1979; Kraus and Loper 1992; Loper et al. 2007). Proceeding studies found that Pf-5 disease suppression was also evident for a myriad of soilborne pathogens and additional host species such as Pyrenophora tritici-repentis with wheat plants and Sclerotinia homoeocarpa and Drechslera poae with turfgrass (Loper et al. 2007). Due to the wide variety of disease suppression and broad host specificity, Pf-5 has become a common reference strain in biological control studies. In addition, the genome sequence of Pf-5 is complete (Paulsen et al. 2005), making this an ideal reference strain for studies incorporating molecular genetic scales.

In the current study, the number of host plant genes deemed differentially expressed was greatest for roots at 3 days after inoculation relative to later time points and shoots at any collection point. Network algorithms clustered transcripts into five modules. The brown module eigenvalue was correlated with root samples regardless of strain, while the green module

Table 2. Impact of Pf-5 or GM30 co-cultures on a suite of host plant physiological and fitness traits ${ }^{\mathrm{a}}$

\begin{tabular}{|c|c|c|c|c|}
\hline Parameter $^{\mathrm{b}}$ & Control & Pf-5 & GM30 & $P$ value \\
\hline \multicolumn{5}{|l|}{ Fitness traits } \\
\hline Seed (mg/plant) & $166.6(26.6)$ & $120.6(17.7)$ & $118.6(23.9)$ & 0.0001 \\
\hline Plant height (mm) & $346.9(18.2)$ & $302(25.8)$ & $295.7(32.7)$ & 0.0001 \\
\hline Lateral root (number/cm of root length) & $4.93(0.18)$ & $8.7(0.16)$ & $8.0(0.41)$ & 0.004 \\
\hline Leaf number & $29.2(0.7)$ & $25.7(2.24)$ & $23.16(1.7)$ & 0.068 \\
\hline Leaf area $\left(\mathrm{cm}^{2}\right)$ & $14.42(2.0)$ & $15.69(1.9)$ & $10.7(2.0)$ & 0.151 \\
\hline \multicolumn{5}{|l|}{ Physiology } \\
\hline Chlorophyll ( $\left.\mu \mathrm{g} \mathrm{g} \mathrm{FW}^{-1}\right)$ & $598.6(26.1)$ & $532.7(40.7)$ & $469.8(20.8)$ & 0.029 \\
\hline Protein $(\mu \mathrm{g} \mathrm{g} \mathrm{FW}-1)$ & $3,840.8(493.9)$ & $3,897.9(332.3)$ & $3,905.7(310.9)$ & 0.911 \\
\hline $\mathrm{A}_{\mathrm{sat}}\left(\mu \mathrm{mol}^{-2} \mathrm{~s}^{-1}\right)$ & $13.6(1.0)$ & $10.63(0.28)$ & $11.12(0.69)$ & 0.031 \\
\hline
\end{tabular}

${ }^{a}$ All measurements were performed 21 days after the onset of microbial co-culture with plant roots, with the exception of seed collection data. A mock coculture with R2A broth was used as a control. Data are means (standard error) of six plants for all traits except seed production and plant height, which used 12 plants.

${ }^{\mathrm{b}} \mathrm{FW}=$ fresh weight. $\mathrm{CO}_{2}$ assimilation was estimated at light saturating conditions $\left(\mathrm{A}_{\text {sat }}\right)$ for the entire rosette using a whole-plant chamber. 
was only correlated with root samples inoculated with GM30 and not Pf-5. This indicates that there were both conserved and strain-dependent aspects of the network architecture. Bioinformatic enrichment analyses indicated that the subnetworks induced by both GM30 and Pf-5 were enriched for RNA regulation, protein degradation, and hormonal metabolism, yet strain specificity was observed in calcium signaling, sugar and nutrient signaling, and auxin metabolism for the GM30 strain. The hub gene with the highest degree of within-module membership (most connected to all other genes within the green module) was GH3 (PBS3; At5g13320). In Arabidopsis, GH3 constitutes a 19-member protein family with several members able to adenylate the plant hormones IAA, SA, and JA (Staswick et al. 2005; Staswick et al. 2002). Previous investigations with pbs3 (At5g13320) lack-of-function mutants found that plants had reduced total SA, failed to accumulate pathogen-induced SA, did not activate defense-related genes and, had compromised resistance (Jagadeeswaran et al. 2007; Lee et al. 2007; Nobuta et al. 2007).

In contrast to strain-specific networks found within roots, there was only one network module with a significant eigenvalue correlation with shoots, and this correlation was independent of strain. Furthermore, data mining from the few transcript-profiling experiments with plant-growth-promoting Pseudomonads (Cartieaux et al. 2003; Verhagen et al. 2004; Wang et al. 2005) found overlap with their differentially expressed genes and membership within the turquoise subnetwork. This raises the question of whether a single subnetwork is driving the systemic response in host plant shoots, and its role in the reprogramming of primary metabolism and physiology. Bioinformatic enrichment analysis found this module to be enriched for genes participating in secondary metabolism, including sulfur-containing glucosinolates, photosynthetic light reactions, and hormone metabolism. Genes with high module membership included those annotated for secondary metabolism in wax production (At1g68530), carotenoid synthesis (At5g57030), and ethylene synthesis (At5g59540).

These observations are consistent with previous investigations that have identified a role for cuticle wax in disease (Jenks et al. 1994) and insect susceptibility (Eigenbrode and Espelie 1995). Plant defenses have been known to be regulated, in part, by ethylene for some time (Ecker and Davis 1987). In addition to carotenoids playing a role in photoprotection, they are also key players in plant defense (Bouvier et al. 2005). To our surprise, however, the most connected hub gene within this module is annotated as a chlorophyll-binding protein for the photosystem II light-harvesting complex. Investigations concerning PGPR on photosynthetic regulation are extremely sparse. In one example, Zhang and associates (2008) found that Bacillus subtilis GB03 increased Arabidopsis photosynthetic efficiency through modulation of sugar (glucose) and $\mathrm{ABA}$ signaling pathways.

\section{What are the consequences of GM30- and Pf-5-induced defense response on host plant primary metabolism and physiology?}

Inoculation of GM30 and Pf-5 with plant roots in our axenic system elicited a systemic network that influenced primary metabolism in plant shoots. Our integrated transcript and metabolite profiling approach revealed alterations in host plant carbohydrate and amino acid metabolism. Changes in measured carbohydrate responses were conserved between strains while strain-specific responses were evident in tryptophan and phenylalanine abundance. Previous metabolite profiling studies found alterations in carbohydrate and amino acid metabolism with Arabidopsis plants treated with benzothiadiazole, a known systemic defense elicitor in the SA pathway (Hien Dao et al. 2009), and methyl jasmonate, a known systemic defense elicitor that is independent of SA (Hendrawati et al. 2006). Although neither study reported significant changes in phenylalanine, methyl jasmonate-treated plants caused an increase in tryptophan similar to our GM30-inoculated plants (Hendrawati et al. 2006).

A role for the tryptophan biosynthetic pathway in plant defense-related regulation has been suggested previously (Niyogi and Fink 1992). More recent studies have shown that the only known secondary metabolite with antimicrobial activity in Arabidopsis (phytoalexins) is an indole derivative known as camalexin. This metabolite is initially derived from tryptophan by CYTOCHROME P450, CYP79B3, and CYP79B2 (Hull et al. 2000; Mikkelsen et al. 2000, 2003). Furthermore, tryptophan-derived indole conjugates have been shown to increase in abundance relative to other classes of glucosinolates (i.e., aliphatic) in Arabidopsis plants treated with methyl jasmonate (Mikkelsen et al. 2003).

Phenylalanine was abundant in shoots of plants inoculated with GM30 but not those inoculated with Pf-5. Phenylalanine is the entry point to the phenylpropanoid pathway that plays an important role in resistance to pathogen attack through multiple mechanisms (Dixon et al. 2002; Naoumkina et al. 2010). This includes the production of monolignols for the subsequent lignification of cell walls, thereby providing mechanical resistance to pathogens (Bechinger et al. 1999). In addition to providing a physical barrier, pathway precursors may also function in chemical defense (Akiyama et al. 2007; Carpinella et al. 2005; Naoumkina et al. 2010). Infiltration of Arabidopsis leaves with flagellin (flg22) results in rapid induction of transcripts for the monolignol biosynthesis enzyme caffeic acid 3-Omethyltransferase. Furthermore, phenylalanine is the precursor to coumarins and flavonoids, both of which appear to play a role in disease resistance (Chong et al. 2002; Cushnie and Lamb 2005; Naoumkina et al. 2010).

Both strains used as inoculates in the soil-based system reduced host plant carbon gain (photosynthesis) and seed production, yet provided a clear fitness benefit when plants were challenged with the bacterial pathogen Pseudomonas syringae DC3000. Numerous studies have suggested that the expression of defense compounds such as those in SAR is metabolically costly (Baldwin and Callahan 1993; Heil et al. 2000; Zangerl et al. 1997). The expression of pathogenesis-related proteins, for example, can represent up to $10 \%$ of the total soluble protein in an infected plant leaf (Heil and Bostock 2002). Arabidopsis plants modified to constitutively express defense-related genes had reduced fitness attributes, whereas mutants incapable of defense signaling exhibited increased growth and reproductive fitness under nonpathogen conditions (Heil and Baldwin 2002. An alternative plant defense strategy to SAR is primed defense, ISR, where plants maintain a heightened state of readiness for pathogen attack. This strategy alleviates the need to maintain costly defense proteins until the pathogen is detected, and has been shown to incur a slight fitness cost relative to SAR (van Hulten et al. 2006). The strain Pf-5 is known to induce ISR and our gene expression results suggest that GM30 also elicits the ISR pathway, given that the JA marker PDF1.2 was induced. However, considerable cross-talk exists between ISR and SAR pathways, requiring mutant analysis to decipher defense pathway signaling with confidence. Further complicating the link between defense pathways, metabolism, and physiology is the possibility that some of the responses may be independent of defense signaling. Nonetheless, our results are consistent with those from the literature and corroborate the notion that primed defense does, indeed, result in decreased carbon gain and seed production, our proxies for fitness, yet it provides a strong benefit to the plant after pathogen challenge. 


\section{MATERIALS AND METHODS}

\section{Plant sample collection and bacterial isolation.}

Root samples were collected from a mature Populus deltoides tree $\left(36^{\circ} 6^{\prime} \mathrm{N}, 85^{\circ} 50^{\prime} \mathrm{W}\right)$ in October 2009 near the Caney Fork River in the Buffalo Valley Recreation Area within DeKalb County, TN. Root samples were processed as described (Gottel et al. 2011). After surface sterilization, the fine roots were pulverized with a sterile mortar and pestle in $10 \mathrm{ml}$ of $\mathrm{MgSO}_{4}(10$ $\mathrm{mM}$ ) solution. The large debris was allowed to settle and aliquots $(100 \mu \mathrm{l})$ were plated on YM agar. Resulting colonies were picked and restreaked a minimum of three times.

\section{Bacterial strains and cultivation.}

P. fluorescens Pf-5/ATCC BAA-477 (Howell and Stipanovic 1979; Paulsen et al. 2005) was purchased from American Type Culture Collection (Manassas, VA, U.S.A.). Pseudomonas sp. GM30 was isolated from poplar rhizosphere samples and is described in the present study. Both strains were routinely cultivated at $25^{\circ} \mathrm{C}$ on R2A (Difco, Detroit) media.

\section{Strain identification and characterization.}

Cells from a 5-ml overnight culture were collected by centrifugation, resuspended in $10 \mathrm{mM}$ Tris, and lysed by boiling for $5 \mathrm{~min}$. The lysate was diluted 1:10 in $10 \mathrm{mM}$ Tris and $1 \mu \mathrm{l}$ was added to a $30-\mu 1$ PCR reaction to amplify the 16S rRNA gene using primers 8F (AGAGTTTGATCCTGGCTCAG) and 1492R (GGTTACCTTGTTACGACTT) at $0.5 \mu \mathrm{M}$ each, 1.25 U of Promega GoTaq Flexi DNA polymerase, $1 \times$ Promega colorless buffer, $2 \mathrm{mM} \mathrm{MgCl} 2,0.2 \mathrm{mM}$ each dNTP, and $10 \mu \mathrm{g}$ of bovine serum albumin. PCR was run on Gene Amp 9700 PCR system (Applied Biosystems, Carlsbad, CA, U.S.A.). The rpoD gene was amplified in a $20-\mu \mathrm{l}$ reaction with M13 fusion primers (rpoD portion is indicated in bold) PsEG30F + M13R (CAGGAAACAGCTATGACCATYGAAATCGCCCAARCG) and PsEG790R+M13F (TGTAAAACGACGGCCAGTCGGT TGATKTCCTTGA) at $0.5 \mu \mathrm{M}$ each using Promega GoTaq Flexi DNA polymerase. Amplification was confirmed by running $5 \mu \mathrm{l}$ of the PCR products on a $1.5 \%$ agarose gel. The remaining product was purified using Multiscreen HTS filter plates (Millipore, Billerica, MA, U.S.A.) and used for Sanger Sequencing with BigDye Terminator v3.1 cycle sequencing kit with the primers 1100R (AGGGTTGCGCTCGTTG), 8F, 1492R, 515F (GTGCCAGCMGCCGCGGTAA), 519R (GWA TTACCGCGGCKGCTG), and 1100F (GGCAACGAGCGMG ACCC). Sequences were ethanol purified and reconstituted in $10 \mu \mathrm{l}$ of HIDI Formamide. The products were run on an ABI3730 sequencer and analyzed with Sequencher 4.9. Production of siderophore was determined using the chrome azurol-S agar assay (Alexander and Zuberer 1991), protease activity was detected using skim milk agar plates (Sokol et al. 1979), phosphatase was detected using Pikovskaya's agar medium (Katznelson and Bose 1959), and IAA was detected by GCMS (described below).

\section{Plant physiology and defense bioassay.}

Plant growth conditions followed that of Wang and associates (2005), where $A$. thaliana seed were germinated and grown under axenic tissue culture conditions for 7 days, transferred to soil medium, and co-cultured with or without rhizobacteria for 21 days. A. thaliana seed of the wild type (Col-0) was obtained from the Arabidopsis Biological Resource Center (ABRC, Columbus, OH, U.S.A.) and surface sterilized using a $100 \%$ ethanol rinse, 8 -min soak in $0.525 \%$ sodium hypochlorite, and $5 \times$ rinse in double-distilled (dd) $\mathrm{H}_{2} \mathrm{O}$. Seed were placed in $\mathrm{ddH}_{2} \mathrm{O}$ water at $4{ }^{\circ} \mathrm{C}$ for 4 days to ensure uniform germination. Seed were germinated in petri dishes with $1 / 2 \times$ Murashige and
Skoog medium (Cassion Laboratories, North Logan, UT, U.S.A.) containing MES hydrate (Sigma-Aldrich, St. Louis) at $0.5 \mathrm{~g} \mathrm{liter}^{-1}$ with $0.5 \%$ (wt/vol) sucrose (Sigma-Aldrich) and $0.7 \%$ (wt/vol) Phytoblend (Cassion Laboratories). Plants were grown vertically at room temperature (approximately $24^{\circ} \mathrm{C}$ ), with photosynthetically active radiation at $100 \mu \mathrm{mol} \mathrm{m}^{-2} \mathrm{~s}^{-1}$ with a photoperiod of $12 \mathrm{~h}$ of light and $12 \mathrm{~h}$ of darkness. After 7 days in petri dishes, plants were dipped in R2A broth with either control (broth only), GM30, or Pf5 containing $10^{8}$ cells $/ \mathrm{ml}$ and were then transferred to pots with double-autoclaved soil (Fafard 3B mix; Agawam, MA, U.S.A.) mix. No additional inoculations were made to the plants throughout the experiment and CFU were $10^{6}$ to $10^{7}$ per gram of root at day 21 post inoculation. After 21 days of plant co-culture with GM30, Pf-5, or broth (R2A) control, plants were evaluated for induction of defense response by challenge with $P$. syringae pv. tomato DC3000 under the following conditions. An overnight culture of $P$. syringae DC3000 was resuspended in 300 $\mathrm{ml}\left(10 \mathrm{mM} \mathrm{MgSO}_{4}+0.015 \%\right.$ Silwet $)$ at $1.0 \mathrm{E}+08 \mathrm{CFU} \mathrm{ml}{ }^{-1}$. Plant leaves were dipped in $P$. syringae DC3000 cell suspension for $30 \mathrm{~s}$. After 5 days of growth, aboveground plant material was harvested and weighed. Plant material was macerated in $1 \mathrm{ml}$ of sterile $\mathrm{diH}_{2} \mathrm{O}$ per $100 \mathrm{mg}$ of plant biomass and serial dilutions were plated on Luria-Bertani plates and incubated at $25^{\circ} \mathrm{C}$.

Leaf gas exchange and estimates of photosynthesis parameters were measured using a Li-6400 Photosynthesis System (LiCor Biosciences, Lincoln, NE, U.S.A.) on the largest leaf, which represented the first fully expanded leaf. Detailed methods for gas exchange have been reported previously (refer to Arabidopsis methods) (Weston et al. 2011). Briefly, cuvette conditions were set for $\mathrm{CO}_{2}$ at $380 \mu \mathrm{mol} \mathrm{mol}^{-1}$ (ambient cuvette concentration), a flow of approximately $500 \mathrm{ml} \mathrm{min}^{-1}$, and relative humidity of 60 to $75 \%$.

\section{Transcript and metabolite profiling.}

A controlled axenic system, similar to that of Leeman and associates (1995), was used to lessen the possibility of airborne contamination for highly responsive transcript and metabolite experiments. Briefly, seed were germinated and grown in tissue culture conditions as above; except, instead of transfer to open soil systems, the seedling roots were dipped in one of the three treatments and placed back into axenic conditions. The axenic system was created using magenta boxes containing autoclaved A3 vermiculite (Whitemore Company, Inc., Lawrence, MA, U.S.A.) saturated with half-strength Hoagland nutrient solution (Hoagland and Arnon 1938) Note that this differs from the Leeman and associates (1995) system in that vermiculite was used instead of rockwool. This system resulted in GM30 and Pf-5 populations of $10^{6}$ to $10^{7} \mathrm{CFU} / \mathrm{g}$ of root. In total, 42 magenta boxes were used and equally divided among three treatments: R2A media control, Pf-5, and GM30. The shoots and roots were spatially separated and preliminary CFU on shoot fresh weight did not detect Pf-5 or GM30. The seedlings were grown for a total of 3, 7, or 10 additional days. Four boxes of each treatment were harvested at $0900 \mathrm{~h}$ on each collection day to minimize confounding inferences from genes and metabolites under diurnal control. Shoots and roots were collected separately and placed at $-80^{\circ} \mathrm{C}$.

\section{RNA isolation, labeling, and microarray hybridization.}

Total RNA was isolated from Arabidopsis shoot and root organs using a Spectrum Plant Total RNA isolation kit (SigmaAldrich) according to the protocol provided, including the optional on-column DNase treatment. Total RNA quantity was determined using a NanoDrop spectrophotometer (Thermo Scientific, Bellefonte, PA, U.S.A.) and RNA quality was as- 
sessed using an Experion RNA StdSens analysis kit and chip (Bio-Rad Laboratories, Hercules, CA, U.S.A.). Only intact RNA samples with an acceptable ratio of optical density at 260/280 $\mathrm{nm}(\geq 1.8)$ were used in subsequent microarray experiments.

Total RNA was converted to amplified (a)RNA using an Amino Allyl MessageAmp II aRNA amplification kit (Ambion, Austin, TX, U.S.A.) according to the provided protocol. The resulting aRNA samples were coupled with either CY3 or CY5 monochromeric dye manufactured by GE Healthcare. Ambion's dye-coupling reaction protocol was modified slightly to accommodate the dye by resuspending lyophilized dye in 88 $\mu \mathrm{l}$ of dimethyl sulfoxide rather than $11 \mu \mathrm{l}$. Labeled aRNA purification was done according to the protocol provided by Ambion and dye incorporation was quantified using a NanoDrop spectrophotometer.

Labeled aRNA (150 pmol) was used for hybridization onto Arabidopsis slides obtained from D. Gailbraith at the University of Arizona. Slides were hybridized and washed according to a published protocol (Weston et al. 2008) using a Maui hybstation and Maui wash station (BioMicro Systems, Inc., Salt Lake City, UT, U.S.A.). Hybridized and washed slides were imaged using a ScanArray Express HT (Perkin Elmer, Waltham, MA, U.S.A.). The resulting images were aligned with design files and data was extracted using GenePix Pro v6.1.0.4.

\section{Microarray data analysis and network construction.}

Log-fold (M) over variance (A) plots (M-A plots) indicated that normexp offset 15 was the most appropriate normalization method. Using the limma package, a linear model was fitted to compare all Arabidopsis co-cultured with Pf-5, GM30, or R2A medium (broth control) as contrasts, and empirical Bayes was used to compute a moderated $t$ statistic according to Smyth (2004, 2005). The broth control was included at each time point on day 3 and 7 to account for possible influences of development on gene expression. All results for differential gene analysis for all contrasts and time points are available in Supplementary Tables S1 and S2.

\section{Network analysis.}

Construction of the weighted gene co-expression network has been described previously (Weston et al. 2008; Zhang and Horvath 2005). Due to computational constraints, the input microarray data were restricted to genes that were significantly differentially expressed in at least one of the three contrasts as defined by treatment. This resulted in a list of 1,700 genes that were entered into network construction. A weighted gene coexpression network consists of four steps i) a pairwise Pearson correlation matrix created for all genes across all treatments, ii) transformation of correlations to connection strengths (connectivity) using a signed power adjacency function, iii) identification of modules or groups of highly correlated gene expression patterns by coupling linkage hierarchical clustering with topological overlap matrix, and iv) relating external gene or treatment information to network properties.

\section{qRT-PCR pathway index.}

A high-throughput robotic qRT-PCR system (7900HT realtime PCR detection system; Applied Biosystems) was used to evaluate multiple marker genes along defined pathways. Total RNA was isolated, and DNase was treated and checked for quality as described above. cDNA synthesis was carried out using a SuperScript III First-Strand Synthesis SuperMix for qRT-PCR (Invitrogen, Carlsbad, CA, U.S.A.) according to the protocol provided. The resulting $21 \mu \mathrm{l}$ of cDNA was diluted in $100 \mu \mathrm{l}$ of $\mathrm{H}_{2} \mathrm{O}$ and used in qRT-PCR reactions.

qRT-PCR was used to compare the relative expression levels of pathway index genes for each of the treated tissues. Ampli- fication reactions $(20 \mu \mathrm{l})$ were carried out using iQ SYBR Green Supermix with reactive oxygen species according to instructions provided by Bio-Rad Laboratories. An Arabidopsis actin gene set (McDowell et al. 1996) was used to normalize the data for differences in input RNA and efficiency of reverse transcription between the samples.

\section{FISH methodology.}

FISH was conducted as described (Watt et al. 2006), with slight modifications. Briefly, roots from control and inoculated Arabidopsis plants were fixed in $4 \%$ paraformaldehyde at $4^{\circ} \mathrm{C}$ for $16 \mathrm{~h}$. The roots were washed in ice cold phosphate-buffered saline and transferred to hybridization buffer $(0.9 \mathrm{M}$ $\mathrm{NaCl}, 20 \mathrm{mM}$ Tris- $\mathrm{HCl}$, and $0.01 \%$ sodium dodecyl sulfate) containing the universal bacterial probe EUB388-Alexa594 (Amann et al. 1990) and a $\gamma$-proteobacteria-specific probe, GAM42a-Alexa488 (Manz et al. 1992), or a Pseudomonas sp.specific probe, PSP1284-Alexa-488 (Gunasekera et al. 2003), for $2 \mathrm{~h}$ at $48^{\circ} \mathrm{C}$. The roots were then transferred to $46^{\circ} \mathrm{C}$ for 15 min. Following hybridization, roots were removed with forceps, excess solution was wicked away, and roots were mounted on $0.4 \%$ gelatin-coated slides for imaging. Roots were imaged using a LSM 710 confocal laser scanning microscope with a Plan-Apochromat $\times 63 / 1.40$ oil immersion objective (Carl Zeiss Microimaging, Thornwood, NY, U.S.A.). Optical sections were collected at $0.5-\mu \mathrm{m}$ spacing and projected as a single xy image using Zen 2009 software (Carl Zeiss Microimaging). Oligonucleotide probes were obtained from Invitrogen.

\section{Metabolic profiling.}

Tissues from the Arabidopsis leaf samples that were collected at 3 and 7 days for the microarray experiment were used for metabolic profiling. We did not, however, process root samples for metabolite analysis because we were unable to discern whether the metabolites are produced by plant or microbial associate. After grinding to a fine powder in liquid nitrogen, approximately 7 to $95 \mathrm{mg}$ of sample tissue (fresh weight) were twice extracted with 2 and $1 \mathrm{ml}$, respectively, in $80 \%$ ethanol overnight and then combined prior to drying a 1-ml aliquot in a nitrogen stream. Sorbitol $(45 \mu \mathrm{l}$ of a $1 \mathrm{mg} / \mathrm{ml}$ aqueous solution) was added before extraction as an internal standard to correct for differences in extraction efficiency, subsequent differences in derivatization efficiency, and changes in sample volume during heating. Dried extracts were dissolved in $500 \mu \mathrm{l}$ of silylation-grade acetonitrile followed by the addition of $500 \mu \mathrm{l}$ of $\mathrm{N}$-methyl- $N$-trimethylsilyltrifluoroacetamide with $1 \%$ trimethylchlorosilane (Thermo Scientific), and samples were then heated for $1 \mathrm{~h}$ at $70^{\circ} \mathrm{C}$ to generate trimethylsilyl (TMS) derivatives (Jung et al. 2009). After 2 days, 1- $\mu$ l aliquots were injected into an Agilent Technologies Inc. (Santa Clara, CA, U.S.A.) 5975C inert XL gas chromatograph-mass spectrometer, fitted with an Rtx-5MS with Integra-guard (5\% diphenyl/95\% dimethyl polysiloxane) capillary column $(30 \mathrm{~m}$ by $250 \mu \mathrm{m}$ by $0.25 \mu \mathrm{m}$ of film thickness). The standard quadrupole GC-MS was operated in the electron impact $(70 \mathrm{eV})$ ionization mode, with six full-spectrum (50- to 650-Da) scans per second. Gas (helium) flow was $1.33 \mathrm{ml} \mathrm{min}^{-1}$ with the injecttion port configured in the splitless mode. The injection port, MS Source, and MS Quad temperatures were 250, 230, and $150^{\circ} \mathrm{C}$, respectively. The initial oven temperature was held at $50^{\circ} \mathrm{C}$ for $2 \mathrm{~min}$, programmed to increase at $20^{\circ} \mathrm{C} \mathrm{min}{ }^{-1}$ to $325^{\circ} \mathrm{C}$ and held for another $11 \mathrm{~min}$, before cycling back to the initial conditions. A large user-created database $(>1,500 \mathrm{spec}-$ tra) of mass spectral electron ionization fragmentation patterns of TMS-derivatized compounds, as well as the Wiley Registry 8th Edition combined with NIST 05 mass spectral database, were used to identify the metabolites of interest to be quanti- 
fied. Peaks were reintegrated and reanalyzed using a key selected ion (characteristic $\mathrm{m} / \mathrm{z}$ fragment) rather than the total ion chromatogram to minimize integrating co-eluting metabolites. The extracted peaks of known metabolites were scaled back up to the total ion current using predetermined scaling factors. The scaling factor for the internal standard (sorbitol) was used for unidentified metabolites. Peaks were quantified by area integration and the concentrations were normalized to the quantity of the internal standard recovered and volume of sample extracted, derivatized, and injected. Four replicate samples were analyzed for each plant type and microbe treatment and the metabolite data were averaged by treatment. Unidentified metabolites were denoted by their retention time as well as key $\mathrm{m} / \mathrm{z}$ fragments.

\section{ACKNOWLEDGMENTS}

This research was sponsored by the Genomic Science Program, U.S. Department of Energy, Office of Science, Biological and Environmental Research, as part of the Plant Microbe Interfaces Scientific Focus Area (based at the Oak Ridge National Laboratory, Oakridge, TN, U.S.A.). Oak Ridge National Laboratory is managed by UT-Battelle LLC, for the U.S. Department of Energy under contract DE-AC05-00OR22725. We thank S. Horvath and P. Lanfelder for collaboration on network analysis; and G. Stacey, S. Karve, and S. Karve for insightful discussions.

\section{LITERATURE CITED}

Akiyama, K., Yamauchi, S., Nakato, T., Maruyama, M., Sugahara, T., and Kishida, T. 2007. Antifungal activity of tetra-substituted tetrahydrofuran lignan, (-)-virgatusin and its structure-activity relationship. Biosci. Biotechnol. Biochem. 71:1028-1035.

Alexander, D. B., and Zuberer, D. A. 1991. Use of chrome azurol S reagents to evaluate siderophore production by rhizosphere bacteria. Biol. Fertil. Soils 12:39-45.

Amann, R. I., Krumholz, L., and Stahl, D. A. 1990. Fluorescent oligonucleotide probing of whole cells for determinative, phylogenetic and environmental studies in microbiology. J. Bacteriol. 172:762-770.

Bakker, P. A. H. M., Pieterse, C. M. J., and van Loon, L. C. 2007. Induced systemic resistance by fluorescent Pseudomonas spp. Phytopathology 97:239-243.

Baldwin, I. T., and Callahan, P. 1993. Autotoxicity and chemical defensenicotine accumulation and carbon gain in Solanaceous plants. Oecologia 94:534-541.

Barabasi, A.-L., and Oltvai, Z. N. 2004. Network biology: Understanding the cell's functional organization. Nat. Rev. Genet. 5:101-113.

Bashan, Y., Holguin, G., and de-Bashan, L. E. 2004. Azospirillum-plant relationships: Physiological, molecular, agricultural and environmental advances (1997-2003). Can. J. Microbiol. 50:521-577.

Bechinger, C., Giebel, K. F., Schnell, M., Leiderer, P., Deising, H. B., and Bastmeyer, M. 1999. Optical measurements of invasive forces exerted by appressoria of a plant pathogenic fungus. Science 285:18961899.

Bouvier, F., Isner, J. C., Dogbo, O., and Camara, B. 2005. Oxidative tailoring of carotenoids: A prospect towards novel functions in plants. Trends Plant Sci. 10:187-194.

Carpinella, M. C., Ferrayoli, C. G., and Palacios, S. M. 2005. Antifungal synergistic effect of scopoletin, a hydroxycoumarin isolated from Melia azedarach L. fruits. J. Agric. Food Chem. 53:2922-2927.

Cartieaux, F., Thibaud, M. C., Zimmerli, L., Lessard, P., Sarrobert, C., David, P., Gerbaud, A., Robaglia, C., Somerville, S., and Nussaume, L. 2003. Transcriptome analysis of Arabidopsis colonized by a plantgrowth promoting rhizobacterium reveals a general effect on disease resistance. Plant J. 36:177-188.

Cartieaux, F., Contesto, C., Gallou, A., Desbrosses, G., Kopka, J., Taconnat, L., Renou, J. P., and Touraine, B. 2008. Simultaneous interaction of Arabidopsis thaliana with Bradyrhizobium sp. strain ORS278 and Pseudomonas syringae pv. tomato DC3000 leads to complex transcriptome changes. Mol. Plant-Microbe Interact. 21:244259.

Chong, J., Baltz, R., Schmitt, C., Beffa, R., Fritig, B., and Saindrenan, P. 2002. Downregulation of a pathogen-responsive tobacco UDPGlc:phenylpropanoid glucosyltransferase reduces scopoletin glucoside accumulation, enhances oxidative stress and weakens virus resistance. Plant Cell 14:1093-1107.

Cushnie, T. P., and Lamb, A. J. 2005. Antimicrobial activity of flavonoids.
Int. J. Antimicrob. Agents 26:343-356.

Dixon, R. A., Achnine, L., Kota, P., Liu, C. J., Reddy, M. S. S., and Wang, L. J. 2002. The phenylpropanoid pathway and plant defence-a genomics perspective. Mol. Plant Pathol. 3:371-390.

Durrant, W. E., and Dong, X. 2004. Systemic acquired resistance. Annu. Rev. Phytopathol. 42:185-209.

Ecker, J. R., and Davis, R. W. 1987. Plant defense genes are regulated by ethylene. Proc. Natl. Acad. Sci. U.S.A. 84:5202-5206.

Eigenbrode, S. D., and Espelie, K. E. 1995. Effects of plant epicuticular lipids on insect herbivores. Annu. Rev. Entomol. 40:171-194.

Gang, W., Kloepper, J. W., and Tuzun, S. 1991. Induction of systemic resistance of cucumber to Colletotrichum orbiculare by select strains of plant growth-promoting rhizobacteria. Phytopathology 81:15081512 .

Gottel, N. R., Castro, H. F., Kerley, M., Yang, Z. M., Pelletier, D. A., Podar, M., Karpinets, T., Uberbacher, E., Tuskan, G. A., Vilgalys, R., Doktycz, M. J., and Schadt, C. W. 2011. Distinct microbial communities within the endosphere and rhizosphere of Populus deltoides roots across contrasting soil types. Appl. Environ. Microbiol. 77:59345944.

Gunasekera, T. S., Dorsch, M. R., Slade, M. B., and Veal, D. A. 2003. Specific detection of Pseudomonas spp. in milk by fluorescence in situ hybridization using ribosomal RNA directed probes. J. Appl. Microbiol. 94:936-945.

Handelsman, J., and Stabb, E. V. 1996. Biocontrol of soilborne plant pathogens. Plant Cell 8:1855-1869.

Heil, M., and Baldwin, I. T. 2002. Fitness costs of induced resistance: Emerging experimental support for a slippery concept. Trends Plant Sci. 7:61-67.

Heil, M., and Bostock, R. M. 2002. Induced systemic resistance (ISR) against pathogens in the context of induced plant defences. Ann. Bot. London 89:503-512.

Heil, M., Hilpert, A., Kaiser, W., and Linsenmair, K. E. 2000. Reduced growth and seed set following chemical induction of pathogen defence: Does systemic acquired resistance (SAR) incur allocation costs? J. Ecol. 88:645-654.

Hendrawati, O., Yao, Q. Q., Kim, H. K., Linthorst, H. J. M., Erkelens, C., Lefeber, A. W. M., Choi, Y. H., and Verpoorte, R. 2006. Metabolic differentiation of Arabidopsis treated with methyl jasmonate using nuclear magnetic resonance spectroscopy. Plant Sci. 170:1118-1124.

Hien Dao, T. T., Puig, R. C., Kim, H. K., Erkelens, C., Lefeber, A. W., Linthorst, H. J., Choi, Y. H., and Verpoorte, R. 2009. Effect of benzothiadiazole on the metabolome of Arabidopsis thaliana. Plant Physiol. Biochem. 47:146-152.

Hoagland, D. R., and Arnon, D. I. 1938. The water culture method for growing plants without soil. Calif. Agric. Exp. Stn. Bull 347:36-39.

Howell, C. R., and Stipanovic, R. D. 1979. Control of Rhizoctonia solani on cotton seedlings with Pseudomonas fluorescens and with an antibiotic produced by the bacterium. Phytopathology 69:480-482.

Hull, A. K., Vij, R., and Celenza, J. L. 2000. Arabidopsis cytochrome $\mathrm{P} 450$ s that catalyze the first step of tryptophan-dependent indole-3acetic acid biosynthesis. Proc. Natl. Acad. Sci. U.S.A. 97:2379-2384.

Jagadeeswaran, G., Raina, S., Acharya, B. R., Maqbool, S. B., Mosher, S. L., Appel, H. M., Schultz, J. C., Klessig, D. F., and Raina, R. 2007. Arabidopsis GH3-LIKE DEFENSE GENE 1 is required for accumulation of salicylic acid, activation of defense responses and resistance to Pseudomonas syringae. Plant J. 51:234-246.

Jenks, M. A., Joly, R. J., Peters, P. J., Rich, P. J., Axtell, J. D., and Ashworth, E. N. 1994. Chemically induced cuticle mutation affecting epidermal conductance to water vapor and disease susceptibility in Sorghum bicolor (L.) Moench. Plant Physiol. 105:1239-1245.

Jung, H. W., Tschaplinski, T. J., Wang, L., Glazebrook, J., and Greenberg, J. T. 2009. Priming in systemic plant immunity. Science 324:89-91.

Katznelson, H., and Bose, B. 1959. Metabolic activity and phosphate dissolving capability of bacterial isolates from wheat roots, rhizosphere and non-rhizosphere soil. Can. J. Microbiol. 5:79-85.

Kim, Y. C., Leveau, J. H. J., Pierson, E. A., Pierson, L. S., Ryu, C. M., and Gardener, B. B. M. 2011. The multifactorial basis for plant health promotion by plant-associated bacteria. Appl. Environ. Microbiol. 77:15481555 .

Kloepper, J. W., and Schroth, M. N. 1978. Plant growth-promoting rhizobacteria on radishes. In: Proc. 4th Int. Conf. Plant Pathogenic Bacteria, Station de Pathologie Vegetale et Phytobacteriologie, INRA, Angers, France.

Kraus, J., and Loper, J. E. 1992. Lack of evidence for a role of antifungal metabolite production by Pseudomonas fluorescens Pf-5 in biological control of Pythium damping-off of cucumber. Phytopathology 82:264271.

Kwon, S. W., Kim, J. S., Park, I. C., Yoon, S. H., Park, D. H., Lim, C. K., and Go, S. J. 2003. Pseudomonas koreensis sp. nov., Pseudomo- 
nas umsongensis sp. nov. and Pseudomonas jinjuensis sp. nov., novel species from farm soils in Korea. Int. J. Syst. Evol. Microbiol. 53:2127.

Lee, M. W., Lu, H., Jung, H. W., and Greenberg, J. T. 2007. A key role for the Arabidopsis WIN3 protein in disease resistance triggered by Pseudomonas syringae that secrete AvrRpt2. Mol. Plant-Microbe Interact. 20:1192-1200.

Leeman, M., Vanpelt, J. A., Denouden, F. M., Heinsbroek, M., Bakker, P. A. H. M., and Schippers, B. 1995. Induction of systemic resistance by Pseudomonas fluorescens in radish cultivars differing in susceptibility to Fusarium wilt, using a novel bioassay. Eur. J. Plant Pathol. 101:655664

Loper, J. E., Kobayashi, D. Y., and Paulsen, I. T. 2007. The genomic sequence of Pseudomonas fluorescens Pf-5: Insights into biological control. Phytopathology 97:233-238.

Lugtenberg, B., and Kamilova, F. 2009. Plant-growth-promoting rhizobacteria. Annu. Rev. Microbiol. 63:541-556.

Manz, W., Amann, R., Ludwig, W., Wagner, M., and Schleifer, K. H. 1992. Phylogenetic oligodeoxynucleotide probes for the major subclasses of proteobacteria—-problems and solutions. Syst. Appl. Microbiol. 15:593600.

McDowell, J. M., Huang, S. R., McKinney, E. C., An, Y. Q., and Meagher, R. B. 1996. Structure and evolution of the actin gene family in Arabidopsis thaliana. Genetics 142:587-602.

Mikkelsen, M. D., Hansen, C. H., Wittstock, U., and Halkier, B. A. 2000. Cytochrome P450 CYP79B2 from Arabidopsis catalyzes the conversion of tryptophan to indole-3-acetaldoxime, a precursor of indole glucosinolates and indole-3-acetic acid. J. Biol. Chem. 275:3371233717.

Mikkelsen, M. D., Petersen, B. L., Glawischnig, E., Jensen, A. B., Andreasson, E., and Halkier, B. A. 2003. Modulation of CYP79 genes and glucosinolate profiles in Arabidopsis by defense signaling pathways. Plant Physiol. 131:298-308.

Naoumkina, M. A., Zhao, Q., Gallego-Giraldo, L., Dai, X., Zhao, P. X., and Dixon, R. A. 2010. Genome-wide analysis of phenylpropanoid defence pathways. Mol. Plant Pathol. 11:829-846.

Nelson, L. M. 2004. Plant growth promoting rhizobacteria (PGPR): Prospects for new inoculants. Crop Management. doi:10.1094/CM-20040301-05-RV. Online publication.

Niyogi, K. K., and Fink, G. R. 1992. Two anthranilate synthase genes in Arabidopsis: Defense-related regulation of the tryptophan pathway. Plant Cell 4:721-733.

Nobuta, K., Okrent, R. A., Stoutemyer, M., Rodibaugh, N., Kempema, L., Wildermuth, M. C., and Innes, R. W. 2007. The GH3 acyl adenylase family member PBS3 regulates salicylic acid-dependent defense responses in Arabidopsis. Plant Physiol. 144:1144-1156.

Osullivan, D. J., and Ogara, F. 1992. Traits of fluorescent Pseudomonas spp. involved in suppression of plant-root pathogens. Microbiol. Rev. 56:662-676

Paulsen, I. T., Press, C. M., Ravel, J., Kobayashi, D. Y., Myers, G. S., Mavrodi, D. V., DeBoy, R. T., Seshadri, R., Ren, Q., Madupu, R., Dodson, R. J., Durkin, A. S., Brinkac, L. M., Daugherty, S. C., Sullivan, S. A., Rosovitz, M. J., Gwinn, M. L., Zhou, L., Schneider, D. J., Cartinhour, S. W., Nelson, W. C., Weidman, J., Watkins, K., Tran, K., Khouri, H., Pierson, E. A., Pierson, L. S., 3rd, Thomashow, L. S., and Loper, J. E. 2005. Complete genome sequence of the plant commensal Pseudomonas fluorescens Pf-5. Nat. Biotechnol. 23:873-878.

Pieterse, C. M. J., VanWees, S. C. M., VanPelt, J. A., Trijssenaar, A., VantWestende, Y. A. M., Bolink, E. M., and VanLoon, L. C. 1996. Systemic resistance in Arabidopsis thaliana induced by biocontrol bacteria. Int. S Crop 61:209-220.

Pieterse, C. M. J., van Wees, S. C. M., van Pelt, J. A., Knoester, M., Laan, R., Gerrits, N., Weisbeek, P. J., and van Loon, L. C. 1998. A novel signaling pathway controlling induced systemic resistance in Arabidopsis. Plant Cell 10:1571-1580.

Pozo, M. J., Van Der Ent, S., Van Loon, L. C., and Pieterse, C. M. J. 2008. Transcription factor MYC2 is involved in priming for enhanced defense during rhizobacteria-induced systemic resistance in Arabidopsis thaliana. New Phytol. 180:511-523.

Saikia, R., Sarma, R. K., Yadav, A., and Bora, T. C. 2011. Genetic and functional diversity among the antagonistic potential fluorescent pseudomonads isolated from tea rhizosphere. Curr. Microbiol. 62:434-444.

Silby, M. W., Cerdeno-Tarraga, A. M., Vernikos, G. S., Giddens, S. R., Jackson, R. W., Preston, G. M., Zhang, X. X., Moon, C. D., Gehrig, S. M., Godfrey, S. A. C., Knight, C. G., Malone, J. G., Robinson, Z., Spiers, A. J., Harris, S., Challis, G. L., Yaxley, A. M., Harris, D., Seeger, K., Murphy, L., Rutter, S., Squares, R., Quail, M. A., Saunders, E., Mavromatis, K., Brettin, T. S., Bentley, S. D., Hothersall, J., Stephens, E., Thomas, C. M., Parkhill, J., Levy, S. B., Rainey, P. B., and Thomson, N. R. 2009. Genomic and genetic analyses of diversity and plant interactions of Pseudomonas fluorescens. Genome Biol. 10:R51.

Smyth, G. K. 2004. Linear models and empirical Bayes methods for assessing differential expression in microarray experiments. Stat. Appl. Genet. Mol. Biol. 3:Article 3. Published online.

Smyth, G. K. 2005. Limma: Linear models for microarray data. Pages 397-420 in: Bioinformatics and Computational Biology Solutions using R and Bioconductor. R. Gentleman, V. Carey, S. Dudoit, R. Irizarry, and W. Huber, eds. Springer, New York.

Soeno, K., Goda, H., Ishii, T., Ogura, T., Tachikawa, T., Sasaki, E., Yoshida, S., Fujioka, S., Asami, T., and Shimada, Y. 2010. Auxin biosynthesis inhibitors, identified by a genomics-based approach, provide insights into auxin biosynthesis. Plant Cell Physiol. 51:524-536.

Sokol, P. A., Ohman, D. E., and Iglewski, B. H. 1979. A more sensitive plate assay for detection of protease production by Pseudomonas aeruginosa. J. Clin. Microbiol. 9:538-540.

Staswick, P. E., Tiryaki, I., and Rowe, M. L. 2002. Jasmonate response locus JAR1 and several related Arabidopsis genes encode enzymes of the firefly luciferase superfamily that show activity on jasmonic, salicylic and indole-3-acetic acids in an assay for adenylation. Plant Cell 14:14051415 .

Staswick, P. E., Serban, B., Rowe, M., Tiryaki, I., Maldonado, M. T., Maldonado, M. C., and Suza, W. 2005. Characterization of an Arabidopsis enzyme family that conjugates amino acids to indole-3-acetic acid. Plant Cell 17:616-627.

Subramanian, A., Tamayo, P., Mootha, V. K., Mukherjee, S., Ebert, B. L., Gillette, M. A., Paulovich, A., Pomeroy, S. L., Golub, T. R., Lander, E. S., and Mesirov, J. P. 2005. Gene set enrichment analysis: A knowledgebased approach for interpreting genome-wide expression profiles. Proc. Natl. Acad. Sci. U.S.A. 102:15545-15550.

Thimm, O., Blasing, O., Gibon, Y., Nagel, A., Meyer, S., Kruger, P., Selbig, J., Muller, L. A., Rhee, S. Y., and Stitt, M. 2004. MAPMAN: A user-driven tool to display genomics data sets onto diagrams of metabolic pathways and other biological processes. Plant J. 37:914939.

Upadhyay, S. K., Singh, D. P., and Saikia, R. 2009. Genetic diversity of plant growth promoting rhizobacteria isolated from rhizospheric soil of wheat under saline condition. Curr. Microbiol. 59:489-496.

Usadel, B., Nagel, A., Steinhauser, D., Gibon, Y., Blasing, O. E., Redestig, H., Sreenivasulu, N., Krall, L., Hannah, M. A., Poree, F., Fernie, A. R., and Stitt, M. 2006. PageMan: An interactive ontology tool to generate, display and annotate overview graphs for profiling experiments. BMC Bioinf. 7:535.

Usadel, B., Obayashi, T., Mutwil, M., Giorgi, F. M., Bassel, G. W., Tanimoto, M., Chow, A., Steinhauser, D., Persson, S., and Provart, N. J. 2009. Co-expression tools for plant biology: Opportunities for hypothesis generation and caveats. Plant Cell Environ. 32:1633-1651.

Vadassery, J., Ranf, S., Drzewiecki, C., Mithofer, A., Mazars, C., Scheel, D., Lee, J., and Oelmuller, R. 2009. A cell wall extract from the endophytic fungus Piriformospora indica promotes growth of Arabidopsis seedlings and induces intracellular calcium elevation in roots. Plant J. 59:193-206.

van Hulten, M., Pelser, M., van Loon, L. C., Pieterse, C. M. J., and Ton, J. 2006. Costs and benefits of priming for defense in Arabidopsis. Proc. Natl. Acad. Sci. U.S.A. 103:5602-5607.

van Loon, L. 2007. Plant responses to plant growth-promoting rhizobacteria. Eur. J. Plant Pathol. 119:243-254.

van Peer, R., Niemann, G. J., and Schippers, B. 1991. Induced resistance and phytoalexin accumulation in biological control of Fusarium wilt of carnation by Pseudomonas sp. strain WCS417r. Phytopathology 81:728-734.

Venieraki, A., Dimou, M., Pergalis, P., Kefalogianni, I., Chatzipavlidis, I., and Katinakis, P. 2011. The genetic diversity of culturable nitrogen-fixing bacteria in the rhizosphere of wheat. Microb. Ecol. 61:277-285.

Verhagen, B. W. M., Glazebrook, J., Zhu, T., Chang, H. S., van Loon, L. C., and Pieterse, C. M. J. 2004. The transcriptome of rhizobacteriainduced systemic resistance in Arabidopsis. Mol. Plant-Microbe Interact. 17:895-908.

Walker, V., Bertrand, C., Bellvert, F., Moenne-Loccoz, Y., Bally, R., and Comte, G. 2011. Host plant secondary metabolite profiling shows a complex, strain-dependent response of maize to plant growth-promoting rhizobacteria of the genus Azospirillum. New Phytol. 189:494-506.

Wang, Y., Ohara, Y., Nakayashiki, H., Tosa, Y., and Mayama, S. 2005. Microarray analysis of the gene expression profile induced by the endophytic plant growth-promoting rhizobacteria, Pseudomonas fluorescens FPT9601-T5 in Arabidopsis. Mol. Plant-Microbe Interact. 18:385-396.

Watt, M., Hugenholtz, P., White, R., and Vinall, K. 2006. Numbers and 
locations of native bacteria on field-grown wheat roots quantified by fluorescence in situ hybridization (FISH). Environ Microbiol. 8:871884.

Weston, D. J., Gunter, L. E., Rogers, A., and Wullschleger, S. D. 2008. Connecting genes, coexpression modules and molecular signatures to environmental stress phenotypes in plants. BMC Syst. Biol. 2:16.

Weston, D. J., Karve, A. A., Gunter, L. E., Jawdy, S. A., Yang, X., Allen, S. M., and Wullschleger S. D. 2011. Comparative physiology and transcriptional networks underlying the heat shock response in Populus trichocarpa, Arabidopsis thaliana and Glycine max. Plant Cell Environ. 34:1488-1506.

Zangerl, A. R., Arntz, A. M., and Berenbaum, M. R. 1997. Physiological price of an induced chemical defense: Photosynthesis, respiration, bio- synthesis and growth. Oecologia 109:433-441.

Zhang, B., and Horvath, S. 2005. A general framework for weighted gene co-expression network analysis. Stat. Appl. Genet. Mol. Biol. 4:Article 17. Published online.

Zhang, H., Xie, X., Kim, M. S., Kornyeyev, D. A., Holaday, S., and Pare, P. W. 2008. Soil bacteria augment Arabidopsis photosynthesis by decreasing glucose sensing and abscisic acid levels in planta. Plant J. $56: 264-273$.

\section{AUTHOR-RECOMMENDED INTERNET RESOURCE}

Plant Microbe Interfaces Scientific Focus Area website: pmi.ornl.gov 